\title{
Transcriptome analysis of the induction of somatic embryogenesis in Coffea canephora and the participation of ARF and Aux/IAA genes
}

\author{
Ana O. Quintana-Escobar ${ }^{1}$, Geovanny I. Nic-Can ${ }^{2}$, Rosa María Galaz Avalos ${ }^{1}$, Víctor M. Loyola-Vargas ${ }^{\text {Corresp., } 1}$, Elsa \\ Gongora-Castillo ${ }^{\text {Corresp. } 3}$ \\ ${ }^{1}$ Unidad de Bioquímica y Biologia Molecular de Plantas, Centro de Investigación Científica de Yucatán, Mérida, Yucatán, México \\ 2 CONACYT Research Fellow-Facultad de Ingeniería Química, Universidad Autónoma de Yucatán, Mérida, Yucatán, Mexico \\ 3 CONACYT Research Fellow-Unidad de Biotecnología, Centro de Investigación Científica de Yucatán, Mérida, Yucatán, México \\ Corresponding Authors: Víctor M. Loyola-Vargas, Elsa Gongora-Castillo \\ Email address: vmloyola@cicy.mx, elsa.gongora@cicy.mx
}

Background. Somatic embryogenesis (SE) is a useful biotechnological tool to study the morpho-physiological, biochemical and molecular processes during the development of Coffea canephora. Plant growth regulators (PGR) play a key role during cell differentiation in SE. The Auxin-response-factor (ARF) and Auxin/Indole-3-acetic acid (Aux/IAA) are fundamental components involved in the signaling of the IAA. The IAA signaling pathway activates or represses the expression of genes responsive to auxins during the embryogenic transition of the somatic cells. The growing development of new generation sequencing technologies (NGS), as well as bioinformatics tools, has allowed us to broaden the landscape of SE study of various plant species and identify the genes directly involved. Methods. Analysis of transcriptome expression profiles of the $C$. canephora genome and the identification of a particular set of differentially expressed genes (DEG) during SE are described in this study. Results. A total of eight ARF and seven Aux/IAA differentially expressed genes were identified during the different stages of the SE induction process. The quantitative expression analysis showed that ARF18 and ARF5 genes are highly expressed after 21 days of the SE induction, while Aux/IAA7 and Aux/IAA12 genes are repressed. Discussion. The results of this study allow a better understanding of the genes involved in the auxin signaling pathway as well as their expression profiles during the SE process. 


\section{Transcriptome analysis of the induction of somatic embryogenesis in Coffea canephora and the participation of ARF and Aux/IAA genes}

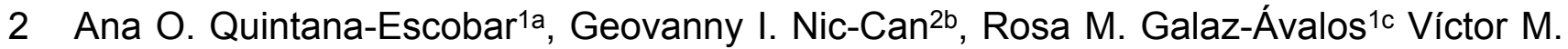
3 Loyola-Vargas $^{1 d}$, Elsa B. Góngora-Castillo ${ }^{3 e}$,

5 1Unidad de Bioquímica y Biología Molecular de Plantas, Centro de Investigación 6 Científica de Yucatán, Mérida, Yucatán, México.

7 2CONACYT Research Fellow-Facultad de Ingeniería Química, Universidad Autónoma 8 de Yucatán, Mérida, Yucatán, México.

$9{ }^{3}$ CONACYT Research Fellow-Unidad de Biotecnología, Centro de Investigación 10 Científica de Yucatán, Mérida, Yucatán, México.

*Correspondence: Elsa Góngora-Castillo, email: elsa.gongora@cicy.mx, and Víctor M. Loyola-Vargas, email: vmloyola@cicy.mx

a ORCID ID, 0000-0003-3686-134x

b ORCID ID, 0000-0001-8003-7716

17 c ORCID ID, 0000-0001-7170-0643

18 d ORCID ID, 0000-0001-5386-4265

19 e ORCID ID, 0000-0001-6327-6993 


\section{Abstract}

24 Background. Somatic embryogenesis (SE) is a useful biotechnological tool to study the 25 morpho-physiological, biochemical and molecular processes during the development of 26 Coffea canephora. Plant growth regulators (PGR) play a key role during cell 27 differentiation in SE. The Auxin-response-factor (ARF) and Auxin/Indole-3-acetic acid 28 (Aux/IAA) are fundamental components involved in the signaling of the IAA. The IAA 29 signaling pathway activates or represses the expression of genes responsive to auxins 30 during the embryogenic transition of the somatic cells. The growing development of new 31 generation sequencing technologies (NGS), as well as bioinformatics tools, has allowed 32 us to broaden the landscape of SE study of various plant species and identify the genes 33 directly involved.

34 35 36

Methods. Analysis of transcriptome expression profiles of the C. canephora genome and the identification of a particular set of differentially expressed genes (DEG) during SE are described in this study.

Results. A total of eight ARF and seven Aux/IAA differentially expressed genes were identified during the different stages of the SE induction process. The quantitative expression analysis showed that ARF18 and ARF5 genes are highly expressed after 21 days of the SE induction, while Aux/IAA7 and Aux/IAA12 genes are repressed.

Discussion. The results of this study allow a better understanding of the genes involved in the auxin signaling pathway as well as their expression profiles during the SE process.

Keywords: auxin response, cellular differentiation, cellular totipotency, growth regulators, signaling, somatic embryogenesis. 
48

49

50

51

52

53

54

55

56

57

58

59

60

61

62

63

64

65

66

67

68

69

70

71

72

73

74

75

76

\section{Introduction}

Coffee is one of the most important crops worldwide. It is cultivated in more than 80 countries, occupying 11 million ha in Africa, Asia, and America (Denoeud et al., 2014; ICO, 2019). World sales are estimated to be 27,200 million U.S. dollars with the employment of approximately 100 million people for cultivation and management (Bunn et al., 2015; ICO 2019). Most of the world's production [168 million bags of $60 \mathrm{~kg}$ coffee beans in 2018; (ICO 2019)] is located in small rural areas; this represents a source of income and family business for millions of people (Martins et al., 2017; ICO 2019).

The Coffea genus is composed of more than 100 species of perennial woody trees (Davis et al., 2006), of which C. arabica and C. canephora predominate in the world coffee trade, with 63 and $37 \%$ of the production, respectively (ICO 2019).

To cover the need for selection programs and market demands, massive propagation techniques such as somatic embryogenesis (SE) have made it possible to obtain a large number of plants of different species, including coffee (Etienne et al., 2013; Loyola-Vargas et al., 2016). Due to the global importance of the coffee crop, SE has been used for productive and commercial purposes in Central America since 2006 and in Mexico since 2012. However, despite the advantages of using SE as a tool for massive plant propagation, it is still necessary to optimize the scale-up of the process (Etienne et al., 2013). Therefore, in depth knowledge of the genetic and molecular mechanisms that control this process could provide useful information to optimize the SE process. It is of particular interest to understand the changes in the genetic program that allow a somatic cell to become an embryo.

SE is a process that can occur both in nature (Kalanchoe genus) (Garcês et al., 2007) and has been translated into laboratories under controlled conditions (Loyola-Vargas \& Ochoa-Alejo, 2016). Briefly, the SE process consists in cultivating somatic cells under the right conditions to give rise to embryogenic cells. These go through a morphophysiological process that produces somatic embryos and later complete plants. Unlike zygotic embryogenesis, where the embryo is inside the seed, making it difficult to study, SE allows easy manipulation and control of the culture conditions for the study of 
77 morpho-physiological, biochemical, and molecular processes that occur during the 78 development in higher plants. The first stage of SE induction has received particular 79 attention, since knowledge of the key steps that change the genetic program of a cell to 80 become an embryo would serve to improve the biotechnological systems of plant 81 regeneration (Wójcikowska \& Gaj, 2017).

82 One of the most important factors during SE induction in different species is the plant 83 growth regulators (PGR) treatment. The use of $P G R$ has been reported in 84 approximately $80 \%$ of the protocols for SE induction (Nic-Can \& Loyola-Vargas, 2016). 85 Most of the PGRs used are auxins, alone or in combination with other regulators, and it 86 is known that there are auxin-related mechanisms functioning through all of the stages 87 of SE induction (Wójcikowska \& Gaj 2017). Different components are involved in the 88 mechanism of regulation of the auxins' response genes (Weijers \& Wagner, 2016; 89 Sghaier et al., 2018), in which the key proteins are Transport Inhibitor Resistant 1/Auxin 90 signaling F-Box (TIR1/AFB), Auxin/Indole-3-acetic acid (Aux/IAA) transcriptional co91 regulators, and Auxin Response Factors (ARF) binding proteins (Weijers \& Wagner 92 2016).

93 At low auxin levels, the Aux/IAA proteins form dimers with the ARFs to inhibit ARF 94 activity by binding with the TPL co-repressor (TOPLESS), which results in the 95 repression of the auxin-responsive genes. In contrast, at high auxin levels, Aux/IAA binds to the SCFTIR1/AFB complex and, as a result, this complex is ubiquitinated and 97 degraded by the $26 \mathrm{~S}$ proteasome. Thus, ARF proteins are important for the regulation 98 of the responsive-to-auxin genes during transcription ( $\mathrm{Li}$ et al., 2016). Integrating the 99 different layers of knowledge related to the regulation of the Aux/IAA system mediated 100 by ARFs is a key priority for a better understanding of cell development in plants ( $\mathrm{Li}$ et 101 al., 2016).

102 The arrival of new generation sequencing technologies (NGS) has allowed the massive 103 sequencing of transcriptomic data, leading to the characterization of important genomic 104 resources with high throughput, sensitivity, accuracy, and low cost (Zhang et al., 2019). 105 RNA-sequencing (RNA-seq) technology has allowed the sequencing of practically any 
106 type of tissue, even uncharacterized biological systems (Ahn et al., 2014), including 107 numerous plant species (Arabidopsis, cotton, oil palm) to study development, 108 senescence, growth, responses to different types of stress, and zygotic and somatic 109 embryogenesis (Chu et al., 2017; Góngora-Castillo et al., 2018). One of the main 110 advantages in using RNA-seq is to identify changes in the genes' expression level 111 under a given condition; for instance, measuring the transcript abundance that controls 112 growth and development of an organism (Rhee, Dickerson, $\mathrm{Xu}, 2006$ ).

113 Several transcriptome studies have been carried out in Coffea species using RNA-seq 114 technology. As a result of these studies it has been possible to identify potential genes 115 related to agronomic traits; as well as unraveling the genetic mechanisms that operate 116 in different processes of the Coffea plant's development, through different explants like 117 leaves, flowers, fruits (Ivamoto et al., 2017;Yuyama et al., 2016) and beans (Cheng, 118 Furtado, Henry, 2017).

119 Although little is known about the molecular mechanism that controls SE, NGS and 120 RNA-seq have broadened the scope for studying the first stages of the SE process. 121 Using the RNA-seq approach, it has been possible to identify a set of genes involved in 122 the embryogenic response in species such as cotton (Cheng et al., 2016; Cao et al., 123 2017), conifers (Yakovlev et al., 2016), papaya (Jamaluddin, Mohd Noor, Goh, 2017), 124 wheat (Chu et al., 2017), and banana (Enríquez-Valencia et al., 2019), among others 125 like Arabidopsis, oil palm, soybean, carrot, grape, alfalfa, and maize (Cetz-Chel \& 126 Loyola-Vargas, 2016; Shi et al., 2016; Tao et al., 2016; Góngora-Castillo et al., 2018). 127 Thus, the aim of this study is to provide a better understanding of the role of auxins 128 during the induction of SE by identifying differentially expressed genes of Coffea 129 canephora when analyzing different stages of SE induction. Particularly, it is our 130 intention to understand the changes in the expression profile of ARF and Aux/IAA 131 genes, which can be associated to the changes observed in the phenotype during SE.

\section{Materials and methods}

\section{Biological material and induction of somatic embryogenesis}


134 The SE induction methodology was carried out according to Quiroz-Figueroa (2006).

135 Briefly, the plantlets were subcultured every four weeks in the maintenance medium 136 without PGR and incubated under photoperiod conditions $\left(150 \mu \mathrm{mol} \mathrm{m} \mathrm{m}^{-2} \mathrm{~s}^{-1}\right) 16 \mathrm{~h}$ light/8

$137 \mathrm{~h}$ dark at $25 \pm 2{ }^{\circ} \mathrm{C}$. To initiate the induction process, the seedlings were previously 138 incubated for 14 days in the pre-conditioning medium [MS salts (Phyto Technology 139 Laboratories, M524), supplemented with $29.6 \mu \mathrm{M}$ thiamin-HCl (Sigma, T3902), $550 \mu \mathrm{M}$ 140 myo-inositol (Sigma, 15125), $0.15 \mu \mathrm{M}$ cysteine (Sigma, C8277), $16.24 \mu \mathrm{M}$ nicotinic acid 141 (Sigma, N4126), $9.72 \mu \mathrm{M}$ pyridoxine-HCl (Sigma, P9755), $87.64 \mathrm{mM}$ sucrose (Sigma, 142 S539) and $0.285 \%$ (w/v) Gellan gum (PhytoTechnology Laboratories, G434), combined 143 with $0.54 \mu \mathrm{M}$ naphthaleneacetic acid (NAA; Sigma, N1145) and $2.32 \mu \mathrm{M}$ kinetin (KIN; 144 Sigma, K0753) adjusted to $\mathrm{pH}$ 5.8], and incubated under the same conditions 145 mentioned above. After 14 days of pre-conditioning, leaves of the second and third pairs 146 were selected in a basipetal direction, and circular explants of eight $\mathrm{mm}$ in diameter 147 were cut with the help of a sterile punch. Five explants per $250 \mathrm{~mL}$ flask were placed 148 with $50 \mathrm{~mL}$ of liquid induction culture medium [Yasuda's medium salts (1985)] 149 supplemented with $5 \mu \mathrm{M}$ benzyladenine (BA; PhytoTechnology Laboratories, B800) at $150 \mathrm{pH}$ 5.8]. The flasks were incubated in the dark at $25 \pm 2{ }^{\circ} \mathrm{C}$ and shaking $(60 \mathrm{rpm})$ for 56 151 days.

\section{Tissue sampling, RNA extraction and sequencing}

153 For RNA extraction and subsequent transcriptome sequencing, $100 \mathrm{mg}$ tissue from $C$. 154 canephora were sampled: i) before SE induction (pre-embryogenic treatment) at 14 155 days before the induction (DBI), 9 and $0 \mathrm{DBI}$; and ii) under embryogenic conditions at 1 156 day after induction (DAI), 2 and 21 DAl. Approximately 12 explants of $0.78 \mathrm{~cm}^{2}$ for each 157 time-point (14, 9, $0 \mathrm{DBI}$ and 1 and $2 \mathrm{DAl}$ ) and $100 \mathrm{mg}$ of pro-embryogenic mass (21 158 DAI) were pooled together to obtain total RNA. For the total RNA extraction, Isolate II 159 RNA Plant Kit (Bioline) and treatment of the sample with DNase I, according to the 160 manufacturer's instructions, were used. The quality of total RNA was verified on 161 agarose gel at 1.5\% and a Nanodrop (Thermo Fischer Scientific) was used to quantify 162 the RNA. Applied Biological Materials Inc. services were used for RNA-seq library 163 preparation and sequencing (https://www.abmgood.com). Briefly, the integrity of total 
164 RNA was assessed using the Agilent 2100 Bioanalyzer with RNA 6000 pico kit (Agilent) 165 before the library construction. RNA samples with an RNA integrity number $\geq 7.5$ were 166 subjected to polyA enrichment followed by first and second strand synthesis and PCR 167 amplification.

168 Sequencing and Bioinformatics analysis

169 A total of 12 single-end libraries were sequenced via Illumina ${ }^{\circledR}$ NextSeq ${ }^{\text {TM }} 500$ system 170 to generate millions of raw reads with a length $\geq 200 \mathrm{bp}$. Two technical sequencing 171 replicates for each biological sample were conducted corresponding to 14,9 and 0 days 172 before induction, and 1, 2 and 21 days after induction. The reads' quality was 173 corroborated using FastQC (v.0.11.5) (http://www.bioinformatics.babraham.ac.uk/ $174 \mathrm{projects/fastqc/)}$. The sequences were pre-processed to remove Illumina adapters and 175 low quality reads $(Q<20)$ using Cutadapt (v. 1.14) (Martin, 2011) and FASTQ Quality 176 Trimmer (Part of FASTX Toolkit 0.0.14) (http://hannonlab.cshl.edu/fastx_toolkit/), 177 respectively. Filtered sequences were mapped to the reference genome of $C$. 178 canephora (v1.0) available at http://coffee-genome.org (Denoeud et al., 2014; Dereeper 179 et al., 2015) using Bowtie2 (v. 2.3.2) (Langmead \& Salzberg, 2012). Htseq-count (v. 180 0.10.0) (Anders, Pyl, Huber, 2015) was used with default options to quantify the gene 181 expression. Expression counts were normalized by quantile normalization method and 182 transformed by $\log _{2}$. To corroborate replicates' similarity, Pearson's correlation 183 coefficient was calculated using RStudio package (v.1.1.456) (https://www.rstudio.com/; 184 Fig. 1S). Differential expression analyses were performed using DESeq2 R-package 185 (v.1.22.1) with a $P<0.05$ and LFC $\leq 1$ or LFC $\geq 1$ (Love, Huber, Anders, 2014). The 186 heatmaps were generated using the ggplot2 package for $R$ (Wickham, 2016). The 187 InteractiveVenn tool was used to create the Venn diagram (Heberle et al., 2015). The 188 orthology analysis was performed using the program OrthoFinder (v.2.2.7) 189 (http://www.stevekellylab.com/software/orthofinder), comparing the amino acid 190 sequences of ARF and Aux/IAA proteins between C. canephora and Arabidopsis 191 thaliana.

\section{Quantification of relative expression by qPCR}


193 Total RNA samples corresponding to days 14,9 and $0 \mathrm{DBI}$, and 1 and $21 \mathrm{DAl}$ were 194 converted to cDNA with the RevertAid H Minus First Strand cDNA Synthesis kit 195 (Thermo Scientific, K1632) and quantified in a Nanodrop 2000 (Thermo Scientific). The 196 primers used are listed in Table 1S. Real-time qPCR quantification was performed with 197 the Express Sybr GreenER qPCR Supermix Universal kit (Invitrogen, A10314), on a 198 StepOne Real-Time PCR System (Applied Biosystems) with three replicates per 199 sampling day, using the cyclophilin gene as the internal reference (Goulao, Fortunato,

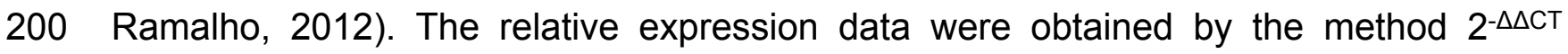
201 (Livak \& Schmittgen, 2001).

\section{Results}

\section{Induction of somatic embryogenesis}

204 SE induction was carried out in leaf explants of C. canephora plantlets cultivated in 205 vitro. In figure 1 we describe how our SE process is divided into two stages, preconditioning and induction, and the characteristics of each one. Plantlets were placed in 207 MS medium supplemented with NAA and KIN for a period of 14 days for pre208 conditioning (before induction) (Fig. 2A). At the end of this stage, the second and third

209 pairs of leaves were used to obtain circular explants. To start the SE induction, the explants were placed in Yasuda's medium added with BA. With a naked eye, no changes were observed in the explants during the first 72 hours of induction. However,

212 apro-embryogenic mass around the explants was observed after 14 days (Fig. 2B, 2C).

213 After 56 days in the induction medium, each one of the explants showed approximately 214300 somatic embryos at different stages of development (globular, heart, torpedo, 215 cotyledonar) located at the periphery and protruding into the culture medium (Fig. 2D). 216 To promote germination, the somatic embryos obtained were transferred to MS semi217 solid culture medium free of PGR (Fig. 2E). All of the embryos continued their 218 development until they achieved complete seedlings (Fig. 2F).

219 Analysis of gene expression during the induction of somatic embryogenesis of $C$. canephora 
221 Samples of $C$. canephora leaf explants before SE induction (14, 9 and $0 \mathrm{DBI})$ and under 222 embryogenic conditions (1,2 and 21 DAl) were collected for RNA sequencing and 223 analysis. Twelve cDNA libraries were constructed and sequenced with the Illumina 224 HiSeq 500 platform and a total of 534,469,789 reads were obtained and pre-processed 225 for quality. The rate of recovered sequences ranged from 88 to almost $100 \%$ (Table 1). 226 High-quality sequences were mapped to the $C$. canephora genome (Denoeud et al., 227 2014; Dereeper et al., 2015). The results showed an overall alignment rate that ranged 228 from 54 to $77 \%$ (Table 1; Table 2S). The expression abundances were calculated for 229 each transcriptome at different time points and biological replicates were analyzed by 230 Pearson's correlation coefficient. The lowest correlation (0.77) was only obtained for the 231 replicates of day $9 \mathrm{DBI}$; this may be due to technical problems during sequencing, or 232 due to variation in transcript expression (Fig. 1S).

233 As expected, the analysis of abundance expression for each transcriptome showed that 234 important changes occur in the gene expression profiles when the explants are 235 transferred to Yasuda's medium (1 DAl) (Fig 3). Interestingly, the analysis of the 236 expression profiles revealed two well-defined clades based on expression counts. The 237 "yellow" clade shows highly expressed genes in which a set of genes are expressed 238 during the entire process of SE. The "blue" clade shows medium-to-low expressed 239 genes, including off genes. The number of minimally expressed and switched off genes 240 is significantly larger than the number of genes in the "yellow" clade, suggesting that 241 many biological functions might not be involved in the SE process (Fig 3).

\section{Expression profiles of ARF and Aux/IAA gene family in C. canephora genome}

243 The analysis of the C. canephora genome revealed a total of 22 ARF genes. Of these, 24417 were expressed throughout the entire SE process (Fig. 4A). Additionally, 14 Aux/IAA 245 genes were identified and all of them were expressed in at least one point of the SE 246 process (Fig. 4B). An orthology analysis with A. thaliana showed that ARF5, ARF6 and 247 ARF9 genes of $C$. canephora are orthologous to the same ARF in $A$. thaliana, whereas 248 ARF18 (Cc06_g03950) in C. canephora is ortholog to ARF16 in A. thaliana. Similarly, 
249 Aux/IAA7 of $C$. canephora is ortholog to Aux/IAA7 of $A$. thaliana. However, identification 250 of the Aux/IAA12 gene ortholog was not possible (Table S3).

251 The expression profile analysis of ARF genes revealed that the ARF5 gene is minimally 252 expressed in the majority of the stages except in $21 \mathrm{DAl}$, during which it increases its 253 expression level (Fig 4A). There is a correlation between the expression changes of 254 this gene and the appearance of embryonic structures as observed in Fig. 2C. The 255 ARF6 gene is highly expressed in all six stages; however, it reaches its maximum at 2 256 DAl. Conversely, the expression level of the ARF9 gene oscillates over time. The 257 expression of this gene decreases during the pre-conditioning stage $(14,9,0 \mathrm{DBI})$ and 258 then slightly increases in the early stages of induction (1,2 DAI). In the case of the 259 ARF18 gene, its expression decreases considerably from 1 DAl on. The levels of 260 expression of the gene Aux/IAA12 remain stable without notable changes throughout 261 the process, as well as the gene Aux/IAA7, except for $21 \mathrm{DAl}$, when its expression 262 decreases (Fig. 4B).

263 A differential gene expression analysis was performed using the $14 \mathrm{DBI}$ sample as 264 reference control. We used $14 \mathrm{DBI}$ as a control since this is the tissue at the beginning 265 of the experiment, where plantlets are maintained on MS medium without PGR (Fig. 1). 266 Thus, the following comparisons were analyzed to obtain the differentially expressed 267 genes among them (DEG): $14 \mathrm{DBI}$ vs $9 \mathrm{DBI} ; 14 \mathrm{DBI}$ vs $0 \mathrm{DBI} ; 14 \mathrm{DBI}$ vs $1 \mathrm{DAl} ; 14 \mathrm{DBI}$ 268 vs $2 \mathrm{DAl}$; and $14 \mathrm{DBI}$ vs $21 \mathrm{DAl}$ (Fig. 5). The analysis of the pre-conditioning stage (14 $269 \mathrm{DBI}$ vs $9 \mathrm{DBI}$, and $14 \mathrm{DBI}$ vs $0 \mathrm{DBI}$ ) revealed 557 and $26 \mathrm{DEG}$, respectively. 270 Comparisons for the first days of induction (14 DBI vs $1 \mathrm{DAl}$, and $14 \mathrm{DBI}$ vs $2 \mathrm{DAl}$ ) 271 showed an increased number of DEG: 4,570 and 3,286, respectively; and 5,319 DEG 272 were observed for late time of SE induction (14 DBI vs 21 DAI) (Fig. 5). Up- and down273 regulated genes were identified for each comparison. The results showed that 274 approximately $75 \%, 55 \%$ and $56 \%$ of genes were down-regulated when the control ( 14 $275 \mathrm{DBI}$ ) was compared against $9 \mathrm{DBI}, 1 \mathrm{DAl}$ and $2 \mathrm{DAI}$, while comparing $14 \mathrm{DBI}$ vs $21 \mathrm{DAl}$ 276 showed a similar proportion of up- and down-regulated genes, with $51 \%$ and $49 \%$, 277 respectively (Fig. 5). These results are in line with the observations in Fig. 3, in which 278 the transcriptome's profile showed that majority of the genes are down-regulated. Also 
279 in Fig. 3, we can see that the expression pattern of $0 \mathrm{DBI}$ is more similar than the rest of 280 the days to that in $14 \mathrm{DBI}$; this result was confirmed by the DEG analysis at this time (14 $281 \mathrm{DBI}$ vs $0 \mathrm{DAl})$. These results may suggest that the most dramatic changes in gene 282 expression occur during the first days of passing the explants to a new culture media 283 with different composition.

284 A Venn diagram showing the interaction between the DEGs of the different comparison 285 sets was created (Fig. 6). Interestingly, only five genes remain differentially expressed 286 consistently throughout the whole ES process; however, most of them are down287 regulated. These five genes were identified according to the functional annotation as 288 protein involved in salt tolerance SIS (Salt-Induced Serine-rich) (Cc06_g02060), 289 adenine nucleotide alpha hydrolases-like superfamily protein (Cc05_g05700), NAC 290 domain-containing protein (Cc02_g33930), mitogen-activated protein kinase kinase 291 kinase (Cc07_g06080) and a hypothetical protein (Cc00_g04350).

292 Stage-specific genes were identified for each comparison and results revealed that 1 293 DAl and 21 DAl stages showed the bulk of these genes (1,602 and 2,511, respectively) 294 (Fig. 6). Of these, 50.7\% and 64.3\% are up-regulated, and consequently, $49.3 \%$ and 295 $35.7 \%$ are down-regulated at $1 \mathrm{DAl}$ and $21 \mathrm{DAl}$, respectively. These results are 296 consistent with the observed phenotypic variation, since at the 1 DAl stage the explants 297 are changed to Yasuda's induction medium, and at 21 DAl stage embryos are observed 298 surrounding the leaf explant (Fig 2C). Comparisons at 9 DBI and 2 DAI showed 196 and 299289 stage-specific genes, respectively. Of these, $19.9 \%$ were up-regulated and $80.1 \%$ 300 were down-regulated when comparing the control to $9 \mathrm{DBI}$; and $39.4 \%$ were up301 regulated and $60.6 \%$ were down-regulated at the control vs. 2 DAl comparison. 302 Additionally, only one gene was distinguished when comparing the control to $0 \mathrm{DBI}$. 303 This gene was identified as an $A B C$ transporter according to functional annotation, and 304 it is up-regulated at this pre-conditioning stage (Fig. 6).

305 The expression analysis revealed that nine ARFs genes were differentially expressed in 306 three different stages of the SE process. ARF19, ARF4, ARF9, and ARF18 307 (Cc06_g03950) genes were down-regulated, while ARF6, ARF5 and ARF18 
308 (Cc01_g11020) genes were up-regulated. Likewise, seven different Aux/IAAs genes 309 were differentially expressed. IAA9, IAA12, IAA29, and IAA7 were down-regulated, 310 while IAA13, IAA33 and IAA29 genes were up-regulated (Table 2).

\section{Quantification of the level of relative expression}

312 The ARF18 (Cc06_g03950), ARF9 (Cc08_g16330), ARF6 (Cc09_g08740) and ARF5 313 (Cc10_g01900) genes, as well as the Aux/IAA7 (Cc03_g04670) and Aux/IAA12 314 (Cc01_g17790) genes, were selected as candidate genes to measure expression by 315 qPCR (Table S1). The qPCR results showed that most of the ARF genes were less 316 expressed at the pre-conditioning stage (14, 9 and $0 \mathrm{DBI})$ compared to the last day of 317 the induction stage (21 DAI); except for the ARF6 gene, which was highly expressed 318 only at 1 DAl stage, during which the explants are changed to Yasuda's induction 319 medium, suggesting that this gene might play a key role at the first stages of SE 320 induction. As expected, the ARF5, ARF9 and ARF18 (Cc06_g03950) genes increased 321 until $21 \mathrm{DAl}$, while the expression of the ARF6 gene was suppressed entirely (Fig. 7).

322 Conversely, the Aux/IAA7 gene was highly expressed at the pre-conditioning stage and 323 its expression level decreased at the induction stage. The Aux/IAA12 gene expression 324 slightly increased at $9 \mathrm{DBI}$ but then decreased at the induction stage. The results 325 suggest that the Aux/IAA genes play a key role during the pre-conditioning stage of the 326 SE process (Fig. 7). Most of the results for qPCR analysis (Fig. 7) are similar to those 327 found in the expression profile of the transcriptome (Fig. 4), except for the ARF18 gene, 328 where the expression profile is not the same in both analyses. We suggest that this 329 difference between the two analyses is due to a biological variation between the 330 different samples used for each one.

\section{Discussion}

332 With the release of the C. canephora genome (Denoeud et al., 2014), a better 333 understanding of this important crop is made possible. It has certainly expanded the 334 number of questions that can be asked; for instance, what molecular mechanisms are 335 responsible for the changes in a somatic cell that allow it to give rise to an embryogenic 
336 cell? Even though the knowledge related to changes in the genetic program of plant 337 cells has grown exponentially in recent years, there are still several aspects of the 338 process that remain unknown (Fehér, Bernula, Gémes, 2016; Cetz-Chel \& Loyola339 Vargas 2016). Particularly, it is not well understood if the initiation of SE responds to the 340 same set of signals in all the species (Loyola-Vargas et al., 2016; Loyola-Vargas \& 341 Ochoa-Alejo 2016; Kumar \& van Staden, 2017; Sisodia \& Bhatla, 2018).

342 The RNA-Seq technology has allowed us to have a complete picture of the genes 343 expressed during SE induction. Transcriptomic studies have showed that the most 344 important and determining changes begin at the start of the SE induction stage (1 DAI) 345 and at the beginning of the development of the first structures (21 DAl) or, in other 346 words, at the moment of the shift from a non-embryogenic state to an embryogenic one 347 (Cheng et al., 2016; Shi et al., 2016; Tao et al., 2016; Cao et al., 2017; Chu et al., 2017; 348 Enríquez-Valencia et al., 2019). Cao et al. (2017) identified the main regulation phase of 349 SE initiation in cotton to occur between three hours and three days after induction. As is 350 the case in our results, most of the dramatic changes are visualized during the transition 351 from the pre-conditioning stage to the first hours of the induction stage and the 21 DAI 352 where embryogenic structures can be observed.

353 The ARF and Aux/IAA genes play a primordial role in the perception and signaling of 354 auxins and the consequent triggering of cellular responses. However, the importance of 355 the ARFs and Aux/IAA genes in several processes of plant development are still not 356 systematically characterized (Li et al., 2015).

357 Both ARFs and Aux/IAA proteins work as transcriptional regulators. While the Aux/IAA 358 repress the auxin response genes, ARF proteins activate or repress the transcription 359 depending on the middle region structure of the protein (Liscum \& Reed, 2002). Aux/IAA 360 encode short-lived nuclear proteins that act as repressors of auxin-mediated 361 transcriptional activation and, although not all Aux/IAA respond to auxins, those that do 362 differ in their sensitivity and type of activity response to this PGR (Liscum \& Reed 2002). 363 In this way, the Aux/IAA proteins control the expression by means of the ARF protein 364 activity to which they join with different levels of specificity. However, the expression of 
365 a given set of ARF and Aux/IAA genes vary from one species to another, and even from one tissue type to another (Jain \& Khurana 2009; Rademacher et al., 2011).

367 Several studies have allowed the identification of the role of some of the 23 ARFs and 368 29 Aux/IAAs in the presence of auxins at different stages of plant development, using 369 mutants of loss or gain of function in A. thaliana (Liscum \& Reed 2002). To mention a 370 few, ARF5 is critical for the formation of the embryonary axis and the embryogenic root, and the development of the flowers, as well as part of the vascular tissue; ARF6 acts in 372 the maturation of the flowers and, in tomato, ARF9 regulates cell division ( $\mathrm{Li}$ et al., 373 2015; 2016; Weijers \& Wagner 2016; Chen et al., 2017). Regarding Aux/IAA proteins, 374 studies in $A$. thaliana have shown that mutations in the Aux/IAA7 gene produce short 375 hypocotyl phenotypes and deformities in the leaves; mutations in the Aux/IAA12 gene 376 cause root abnormalities (Liscum \& Reed 2002).

377 The ARFs and Aux/IAAs interactions are not well known, but the most studied case is 378 the interaction of the MONOPTEROS (MP/ARF5) and BODENLOS (BDL/IAA12) genes. 379 They are essential effectors of the action of auxins in the embryo. The mutants produce 380 defects in the embryogenic pattern, in particular in the formation of the embryonic axis, 381 the formation of the cotyledons and the apical and radicular meristems (Weijers \& 382 Wagner 2016). The BDL/IAA12 protein usually is degraded in response to auxins; 383 therefore, a mutation in BDL/IAA12 prevents its degradation, causing abnormal 384 embryogenic phenotypes. Until now, the mechanisms of regulation of auxins by other 385 interactions of ARFs and Aux/IAAs directly related to embryogenesis have been 386 unknown (Weijers \& Wagner 2016; Mironova et al., 2017).

387 In our results, we observed a decrease in the expression of Aux/IAA7 and Aux/IAA12 as 388 ARF5, ARF9 and ARF18 (Cc06_g03950) increased (Fig. 7). Mironova et al. (2017) 389 mention that the degradation of Aux/IAA12 associated with the signaling of ARF5 is 390 necessary for auxin signals to be translated into programs of morphogenesis and cell 391 development. Also, it has been determined that MP/ARF5 can self-regulate its 392 transcription and that of BDL/IAA12, as well as that of other Aux/IAA genes, through the 
393 action of auxins. In this way, it is inferred that the auxins function as a trigger causing 394 the degradation of BDL/IAA12 (Chandler, 2016).

395 Wojcikowska et al. (2017) observed that the ARFs that are most expressed during SE in 396 Arabidopsis were ARF5, ARF6, ARF8, ARF10, ARF16 and ARF17, with ARF5 and 397 ARF10 having the highest accumulation of transcripts; while the least expressed were 398 ARF1, ARF2, ARF3, ARF11, and ARF18. Similarly, our differential expression results 399 showed that the highest levels of expression are presented by the ARF5 and ARF6 400 genes (Fig. 4A), as well as by the fact that the ARF2 and ARF18 (Cc06_g03950) are 401 down-regulated (Table 2). However, in the qPCR test, ARF18 (Cc06_g03950) showed 402 the highest relative expression levels, followed by ARF5. Another similarity found was 403 that ARF18 (Cc06_g03950) had a reduction in its activity in the early stages of the 404 induction of SE, similar to the results reported here, although for the last day of the 405 induction process it increased its levels of expression. On the other hand, the ARF5 406 gene also showed higher expression and the level of transcripts increased in the early 407 stages of SE. This observation suggests that there is a close relationship between this 408 gene and the embryogenic transition of the cells.

409 Several studies have demonstrated that ARF6 usually is co-expressed with ARF8. In 410 Dimocarpus longan, an increase of ARF6 is necessary to initiate the development of 411 somatic embryos, while ARF8 is related to the transition to globular and cotiledonar 412 stages in embryos (Lin et al., 2015). In arf6/arf8 Arabidopsis double mutants it was 413 found that ARF6, together with ARF8, plays an important role during SE induction by 414 mediating auxin signaling and leading to the activation of related genes. Also, the 415 production of jasmonic acid decreases, which could be related to the blocking of SE (Su 416 et al., 2016; Kumar \& van Staden 2017).

417 In zygotic embryogenesis it is well documented that ARF9 participates in the 418 suspensors cell as well as in the protoderm of the lower tier in the pro-embryo 419 (Rademacher et al., 2011). However, in SE, ARF9 was found to play significant roles in 420 the regulation of SE induction from Lilium oriental callus by increasing its expression 421 during the first days of culture (Chen et al., 2019). This finding is contrary to our results 
422 that showed that ARF9 had a low expression during the first days of induction. 423 Nevertheless, in oil palm a reduction of ARF9 during the first days of culture in the 424 presence of 2,4-D was found, but after 7 days this condition changed by increasing the 425 expression, suggesting that the ARF9 had overcome an initial suppression due to the 426 addition of exogenous auxin to the culture medium (Ooi et al., 2012). Thus we can 427 suggest a similar situation in our model, since ARF9 expression decreased during the 428 pre-conditioning stage where exogenous auxin was added and rose until the last day of 429 induction.

430 About the expression of the Aux/IAA genes, Yang et al. (2012) observed that most of 431 the transcription of these genes decreased during the transition stage to 432 embryogenesis, although the expression of these genes increased during the 433 development of the embryos. In the same way, our results indicate that Aux/IAA7 and 434 Aux/IAA12 diminish their expression gradually as the induction process of SE 435 progresses, reaching values close to zero.

436 Additionally, of all of the genes differentially expressed, only five remained constant in 437 that condition during the whole process of SE induction. Of these genes, the four 438 described below are related to biotic and abiotic stress responses, and to processes of 439 vegetal development such as embryogenesis.

440 SIS proteins (Salt-Induced Serine-rich) and the adenine nucleotide alpha hydrolase-like 441 superfamily play an important role in the protective function of the endosperm on the 442 embryo (together with other factors and proteins) in Brassica napus (Lorenz et al., 443 2014).

444 Proteins with a NAC domain are transcription factors involved in different processes of 445 plant development and have recently received special attention due to their implication 446 in the responses to biotic and abiotic stress, as well as their interaction with certain 447 PGR. They are also essential regulatory proteins in the process of cell proliferation and 448 plant regeneration (Puranik et al., 2012). Similar to the observations in this work, a NAC 449 protein was identified as differentially expressed during the SE of Citrus sinensis callus 450 (Ge et al., 2012). On the other hand, NAC proteins have been identified as the target 
451 gene of BABY BOOM (BBM). Despite the study being carried out in non-embryonic 452 tissues, it is remarkable the importance of BBM genes during cellular development and 453 embryogenesis in plants (Passarinho et al., 2008). Also, NAC proteins are essential 454 regulators during plant regeneration as found in Arabidopsis stems, where these 455 proteins were expressed when a wound was made on the stem and auxin accumulated 456 to initiate a proliferation process (Ikeuchi, Sugimoto, Iwase, 2013).

457 For its part, the mitogen-activated protein kinase kinase kinase (MAPKKK) play 458 important roles in the transduction of intra- and extracellular signals related to stress 459 and plant cell development by regulating diverse processes, such as the homeostasis of 460 reactive oxygen species and the response to PGR in Arabidopsis (Nakagami et al., 461 2006), leaf senescence, cell division, and lateral root formation, among others (Xu \& 462 Zhang, 2015).

463 Another interesting result found was that, in the comparison $14 \mathrm{DBI}$ vs $0 \mathrm{DBI}$, only one 464 gene was uniquely expressed at this condition which was not present in the other 465 comparisons: an $A B C$ transporter. Members of this family are implicated in the transport 466 of auxinic compounds such as IAA, IBA, and even synthetic analogues (Geisler et al., 467 2017). In a previous study of the endogenous levels of auxins, it was found that during 468 the pre-conditioning stage there is an important increase in IAA and IBA (Ayil-Gutiérrez 469 et al., 2013), so this may suggest the importance of the transporter in the process.

470 The results obtained from this research are relevant since the combination of the pairs 471 of Aux/IAAs and ARFs determine their role during development (Jain \& Khurana 2009). 472 There are two facts to keep in mind: first, if any ARF could interact with any Aux/IAA 473 protein, there would be more than 600 possible pairwise combinations (Weijers et al., 474 2005); second, not all the Aux/IAAs respond to auxin (Paponov et al., 2008). Together, 475 the results presented in this research and those of the literature suggest that the paired 476 Aux/IAAs and ARFs are essential for SE to be carried out.

\section{Conclusion}


478 There are several plant development processes related to auxin signaling mediated by 479 genes from the ARF and Aux/IAA families. The role of each of these genes can vary 480 from one species to another and in the genus Coffea, specifically in the species $C$. 481 canephora, there are no records of their expression during SE. As a first approach, with 482 the use of bioinformatics tools, it was possible to identify ARF and Aux/IAA genes 483 differentially expressed through the entire induction SE process. A family of 22 ARF 484 genes was found in C. canephora genome; 17 are expressed in our study model, and 485 eight of them are differentially expressed in different stages of the SE process. A total of 48614 Aux/IAA genes were found in the C. canephora genome, and although all are 487 expressed in at least one point of the SE process, only seven are differentially 488 expressed. The quantitative analysis by qPCR revealed that the ARF18 (Cc06_g03950) 489 and ARF5 genes are highly expressed at 21 DAl. Conversely, the expression of 490 Aux/IAA7 and Aux/IAA12 genes varies from high to low through the different SE stages. 491 The results presented in this study provide valuable information for our understanding of 492 the underlying molecular mechanisms by which a somatic cell gives rise to an 493 embryogenic cell.

\section{Conflict of interest}

495 The authors declare that the research was conducted in the absence of any commercial 496 or financial relationships that could be construed as a potential conflict of interest.

\section{Author contributions}

498 VMLV and EGC conceived and designed the experiments. RMG-A and GIN-C 499 performed biological experiments. AOQE and EGC realized the bioinformatic analysis. 500 AOQE, EGC, and VMLV drafted the manuscript. All the authors approved the final draft.

\section{Funding}

502 This work was supported by the National Council of Science and Technology (FS-1515 503 to Víctor M. Loyola-Vargas).

504 Supplemental information 
505 The raw data have been deposited in the GEO repository at NCBI 506 (http://www.ncbi.nlm.nih.gov/geo), and are available under the accession number: 507 GSE128888.

508 References

509 Ahn YK, Tripathi S, Kim JH, Cho YI, Lee HE, Kim DS, Woo JG, Cho MC. 2014. 510 Transcriptome analysis of Capsicum annuum varieties Mandarin and Blackcluster: 511 Assembly, annotation and molecular marker discovery. Gene 533(2):494-499 DOI: 512 http://dx.doi.org/10.1016/j.gene.2013.09.095.

513 Anders S, Pyl PT, Huber W. 2015. HTSeq-a Python framework to work with high514 throughput sequencing data. Bioinformatics 31(2):166-169 DOI: 515 https://doi.org/10.1093/bioinformatics/btu638.

516 Ayil-Gutiérrez BA, Galaz-Ávalos RM, Peña-Cabrera E, Loyola-Vargas VM. 2013. 517 Dynamics of the concentration of IAA and some of its conjugates during the induction of 518 somatic embryogenesis in Coffea canephora. Plant Signaling \& Behavior 8(11):e26998 519 DOI: $10.4161 /$ psb.26998.

520 Bunn C, Läderach P, Rivera OO, Kirschke D. 2015. A bitter cup: climate change profile 521 of global production of Arabica and Robusta coffee. Climatic Change 129(1-2):89-101 522 DOI: https://doi.org/10.1007/s10584-014-1306-x.

523 Cao A, Zheng Y, Yu Y, Wang X, Shao D, Sun J, Cui B. 2017. Comparative 524 transcriptome analysis of SE initial dedifferentiation in cotton of different SE capability. 525 Scientific Reports 7:8583 DOI: 10.1038/s41598-017-08763-8.

526 Cetz-Chel JE, Loyola-Vargas VM. 2016. Transcriptome profile of somatic 527 embryogenesis, In: Loyola-Vargas VM, Ochoa-Alejo N eds. Somatic embryogenesis. 528 Fundamental aspects and applications. Switzerland: Springer, 39. DOI: 10.1007/978-3529 319-33705-0_4.

530 Chandler JW. 2016. Auxin response factors. Plant, Cell \& Environment 39(5):10145311028 DOI: $10.1111 /$ pce.12662.

532 Chen M, Zhang J, Zhou Y, Li S, Fan X, Yang L, Guan Y, Zhang Y. 2019. Transcriptome 533 analysis of Lilium Orientale $\mathrm{x}$ Trumpet hybrid roots reveals auxin-related genes and stress-related genes involved in picloram-induced somatic embryogenesis induction.

535 The Journal of Horticultural Science and Biotechnology 94(3):317-330 DOI: 536 https://doi.org/10.1080/14620316.2018.1500086.

537 Chen Z, Yuan Y, Fu D, Shen C, Yang Y. 2017. Identification and expression profiling of 538 the auxin response factors in Dendrobium officinale under abiotic stresses. International 539 Journal of Molecular Sciences 18(5):927 DOI: 10.3390/ijms18050927. 
540 Cheng B, Furtado A, Henry RJ. 2017. Long-read sequencing of the coffee bean 541 transcriptome reveals the diversity of full-length transcripts. GigaScience 6(11):gix086 542 DOI: https://doi.org/10.1093/gigascience/gix086.

543 Cheng WH, Zhu HG, Tian WG, Zhu SH, Xiong XP, Sun YQ, Zhu QH, Sun J. 2016. De 544 novo transcriptome analysis reveals insights into dynamic homeostasis regulation of somatic embryogenesis in upland cotton (G. hirsutum L.). Plant Molecular Biology 92(3):279-282 DOI: 10.1007/s11103-016-0511-6.

547 Chu Z, Chen J, Sun J, Dong Z, Yang X, Wang Y, Xu H, Zhang X, Chen F, Cui D. 2017. 548 De novo assembly and comparative analysis of the transcriptome of embryogenic callus 549 formation in bread wheat (Triticum aestivum L.). BMC Plant Biology 17:244 DOI: 550 https://doi.org/10.1186/s12870-017-1204-2.

551 Davis AP, Govaerts R, Bridson DM, Stoffelen P. 2006. An annotated taxonomic 552 conspectus of the genus Coffea (Rubiaceae). Botanical Journal of the Linnean Society 553 152(4):465-512 DOI: https://doi.org/10.1111/j.1095-8339.2006.00584.x.

554 Denoeud F, Carretero-Paulet L, Dereeper A, Droc G, Guyot R, Pietrella M, Zheng C, 555 Alberti A, Anthony F, Aprea G, Aury JM, Bento P, Bernard M, Bocs S, Campa C, Cenci A, Combes MC, Crouzillat D, Da Silva C, Daddiego L, De Bellis F, Dussert S, Garsmeur O, Gayraud T, Guignon V, Jahn K, Jamilloux V, Joët T, Labadie K, Lan T, Leclercq J, Lepelley M, Leroy T, Li LT, Librado P, Lopez L, Muñoz A, Noel B, Pallavicini A, Perrotta G, Poncet V, Pot D, Priyono, Rigoreau M, Rouard M, Rozas J, Tranchant-Dubreuil C, VanBuren R, Zhang Q, Andrade AC, Argout X, Bertrand B, De Kochko A, Graziosi G, Henry RJ, Jayarama, Ming R, Nagai C, Rounsley S, Sankoff D, Giuliano G, Albert VA, Wincker P, Lashermes P. 2014. The coffee genome provides insight into the convergent evolution of caffeine biosynthesis. Science 345(6201):1181-1184 DOI: 10.1126/science.1255274.

Dereeper A, Bocs S, Rouard M, Guignon V, Ravel S, Tranchant-Dubreuil C, Poncet V, Garsmeur O, Lashermes P, Droc G. 2015. The coffee genome hub: a resource for coffee genomes. Nucleic Acids Research 43(D1):D1028-D1035 DOI: 10.1093/nar/gku1108.

569

570

Enríquez-Valencia AJ, Vázquez-Flota FA, Ku-Cauich JR, Escobedo-GraciaMedrano RM. 2019. Differentially expressed genes during the transition from early to late 571

572 development phases in somatic embryo of banana (Musa spp. AAB group, Silk subgroup) cv. Manzano. Plant Cell, Tissue and Organ Culture 136(2):289-302 DOI: 573 https://doi.org/10.1007/s11240-018-1514-6.

574 Etienne H, Bertrand B, Georget F, Lartaud M, Montes F, Dechamp E, Verdeil JL, Barry575 Etienne D. 2013. Development of coffee somatic and zygotic embryos to plants differs 576 in the morphological, histochemical and hydration aspects. Tree Physiology 33(6):640577653 DOI: 10.1093/treephys/tpt034.

578 Fehér A, Bernula D, Gémes K. 2016. The many ways of somatic embryo initiation, In: 579 Loyola-Vargas VM, Ochoa-Alejo N eds. Somatic Embryogenesis: Fundamental Aspects 
580 and Applications. Cham: Springer International Publishing, 23. DOI: 10.1007/978-3-319581 33705-0_3.

582 Garcês HMP, Champagne CE, Townsley BT, Park S, Malho R, Pedroso MC, Harada $583 \mathrm{JJ}$, Sinha NR. 2007. Evolution of asexual reproduction in leaves of the genus 584 Kalanchoe. Proceedings of the National Academy of Sciences of the United States of 585 America 104(39):15578-15583 DOI: 10.1073/pnas.0704105104.

586 Ge XX, Chai LJ, Liu Z, Wu XM, Deng XX, Guo WW. 2012. Transcriptional profiling of 587 genes involved in embryogenic, non-embryogenic calluses and somatic embryogenesis 588 of Valencia sweet orange by SSH-based microarray. Planta 236(4):1107-1124 DOI: 589 10.1007/s00425-012-1661-7.

590 Geisler M, Aryal B, di Donato M, Hao P. 2017. A critical view on ABC transporters and 591 their interacting partners in auxin transport. Plant and Cell Physiology 58(10):1601-1614 592 DOI: https://doi.org/10.1093/pcp/pcx104.

593 Góngora-Castillo E, Nic-Can GI, Galaz-Ávalos RM, Loyola-Vargas VM. 2018. 594 Elaboration of transcriptome during the induction of somatic embryogenesis, In: Loyola595 Vargas VM, Ochoa-Alejo N eds. Plant Cell Culture Protocols. New York, NY: Springer 596

597

598

599

600

601

602

603

604 New York, 411. DOI: https://doi.org/10.1007/978-1-4939-8594-4_29.

Goulao LF, Fortunato AS, Ramalho JC. 2012. Selection of reference genes for normalizing quantitative real-time PCR gene expression data with multiple variables in Coffea spp. Plant Molecular Biology Reporter 30(3):741-759 DOI: https://doi.org/10.1007/s11105-011-0382-6.

Heberle H, Meirelles GV, da Silva FR, Telles GP, Minghim R. 2015. InteractiVenn: a web-based tool for the analysis of sets through Venn diagrams. BMC Bioinformatics 16(1):169 DOI: https://doi.org/10.1186/s12859-015-0611-3.

605 (Accessed March 2019). ICO

606 Ikeuchi M, Sugimoto K, Iwase A. 2013. Plant callus: mechanisms of induction and 607

608 Ivamoto ST, Júnior OR, Domingues DS, dos Santos TB, de Oliveira FF, Pot D, Leroy T, 609 Vieira LGE, Carazzolle MF, Pereira GAG. 2017. Transcriptome analysis of leaves, 610 flowers and fruits perisperm of Coffea arabica $L$. reveals the differential expression of 611 genes involved in raffinose biosynthesis. PLOS ONE 12(1):e0169595 DOI: 612 https://doi.org/10.1371/journal.pone.0169595.

613 Jain M, Khurana JP. 2009. Transcript profiling reveals diverse roles of auxin-responsive 614 genes during reproductive development and abiotic stress in rice. The FEBS Journal 615 276(11):3148-3162 DOI: 10.1111/j.1742-4658.2009.07033.x. 
616 Jamaluddin ND, Mohd Noor N, Goh HH. 2017. Genome-wide transcriptome profiling of 617 Carica papaya L. embryogenic callus. Physiology and Molecular Biology of Plants 618 23(2):357-368 DOI: 10.1007/s12298-017-0429-8.

619 Kumar V, van Staden J. 2017. New insights into plant somatic embryogenesis: an 620 epigenetic view. Acta Physiologiae Plantarum 39(9):194 DOI: 621 https://doi.org/10.1007/s11738-017-2487-5.

622 Langmead B, Salzberg SL. 2012. Fast gapped-read alignment with Bowtie 2. Nature 623 Methods 9(4):357-359 DOI: 10.1038/nmeth.1923.

624 Li S-B, Ou Yang W-Z, Hou X-J, Xie L-L, Hu C-G, Zhang J-Z. 2015. Genome-wide 625 identication, isolation and expression analysis of auxin response factor (ARF) gene 626 family in sweet orange (Citrus sinensis). Frontiers in Plant Science 6:119 DOI: 627 10.3389/fpls.2015.00119.

628 Li S-B, Xie ZZ, Hu CG, Zhang JZ. 2016. A review of auxin response factors (ARF) in 629 plants. Frontiers in Plant Science 7:47 DOI: 10.3389/fpls.2016.00047.

630 Lin Y, Lai Z, Lin L, Lai R, Tian Q, Ye W, Zhang D, Yang M, Chen Y, Zhang Z. 2015. 631 Endogenous target mimics, microRNA167, and its targets ARF6 and ARF8 during 632 somatic embryo development in Dimocarpus longan Lour. Molecular Breeding 633 35(12):227 DOI: https://doi.org/10.1007/s11032-015-0420-4.

634 Liscum E, Reed JW. 2002. Genetics of Aux/IAA and ARF action in plant growth and 635 development. Plant Molecular Biology 49(3-4):387-400 DOI: 636 10.1023/A:1015255030047.

637 Livak KJ, Schmittgen TD. 2001. Analysis of relative gene expression data using real-

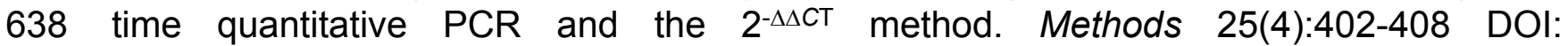
639 http://dx.doi.org/10.1006/meth.2001.1262.

640 Lorenz C, Rolletschek H, Sunderhaus S, Braun HP. 2014. Brassica napus seed 641 endosperm - Metabolism and signaling in a dead end tissue. Journal of Proteomics 642 108:382-426 DOI: 10.1016/j.jprot.2014.05.024.

643 Love MI, Huber W, Anders S. 2014. Moderated estimation of fold change and 644 dispersion for RNA-seq data with DESeq2. Genome Biology 15(12):550 DOI: 645 https://doi.org/10.1186/s13059-014-0550-8.

646 Loyola-Vargas VM, Avilez-Montalvo JR, Avilez-Montalvo RN, Márquez-López RE, 647 Galaz-Ávalos RM, Mellado-Mojica E. 2016. Somatic embryogenesis in Coffea spp., In: 648 Loyola-Vargas VM, Ochoa-Alejo N eds. Somatic embryogenesis. Fundamental aspects 649 and applications. Switzerland: Springer, 241. DOI: 10.1007/978-3-319-33705-0_15.

650 Loyola-Vargas VM,Ochoa-Alejo N. 2016. Somatic embryogenesis. An overview, In: 651 Loyola-Vargas VM, Ochoa-Alejo N eds. Somatic embryogenesis. Fundamental aspects 652 and applications. Switzerland: Springer, 1. DOI: 10.1007/978-3-319-33705-0_1. 
653 Martin M. 2011. Cutadapt removes adapter sequences from high-throughput 654 sequencing reads. EMBnet. Journal 17(1):10-12 DOI:

655 http://dx.doi.org/10.14806/ej.17.1.200.

656 Martins MQ, Fortunato AS, Rodrigues WP, Partelli FL, Campostrini E, Lidon FC, 657 DaMatta FM, Ramalho JC, Ribeiro-Barros Al. 2017. Selection and validation of 658 reference genes for accurate RT-qPCR data normalization in Coffea spp. under a 659 climate changes context of interacting elevated $\left[\mathrm{CO}_{2}\right]$ and temperature. Frontiers in 660 Plant Science 8:307 DOI: 10.3389/fpls.2017.00307.

661 Mironova V, Teale W, Shahriari M, Dawson J, Palme K. 2017. The systems biology of 662 auxin in developing embryos. Trends in Plant Science 22(3):225-235 DOI: 663 http://dx.doi.org/10.1016/j.tplants.2016.11.010.

664 Nakagami H, Soukupová H, Schikora A, Zársky V, Hirt H. 2006. A mitogen-activated 665 protein kinase kinase kinase mediates reactive oxygen species homeostasis in 666 Arabidopsis. Journal of Biological Chemistry 281(50):38697-38704 DOI: 667 10.1074/jbc.M605293200.

668 Nic-Can GI,Loyola-Vargas VM. 2016. The role of the auxins during somatic 669 embryogenesis, In: Loyola-Vargas VM, Ochoa-Alejo N eds. Somatic embryogenesis. 670 Fundamental aspects and applications. Switzerland: Springer, 171. DOI: 10.1007/978671 3-319-33705-0_10.

672 Ooi SE, Choo CN, Ishak Z, Ong-Abdullah M. 2012. A candidate auxin-responsive 673 expression marker gene, EgIAA9, for somatic embryogenesis in oil palm (Elaeis 674 guineensis Jacq.). Plant Cell, Tissue and Organ Culture 110(2):201-212 DOI: 675 10.1007/s11240-012-0143-8.

676 Paponov IA, Paponov M, Teale W, Menges M, Chakrabortee S, Murray JAH, Palme K. 677 2008. Comprehensive transcriptome analysis of auxin responses in Arabidopsis. 678 Molecular Plant 1(2):321-337 DOI: https://doi.org/10.1093/mp/ssm021.

679 Passarinho P, Ketelaar T, Xing M, van Arkel J, Maliepaard C, Hendriks M, Joosen R, 680 Lammers M, Herdies L, den Boer B, van der Geest L, Boutilier K. 2008. BABY BOOM 681 target genes provide diverse entry points into cell proliferation and cell growth 682 pathways. Plant Molecular Biology 68(3):225-237 DOI: 10.1007/s11103-008-9364-y.

683 Puranik S, Sahu PP, Srivastava PS, Prasad M. 2012. NAC proteins: regulation and role 684 in stress tolerance. Trends in Plant Science 17(6):369-381 DOI: 685 https://doi.org/10.1016/j.tplants.2012.02.004.

686 Quiroz-Figueroa FR, Monforte-González M, Galaz-Ávalos RM, Loyola-Vargas VM. 687 2006. Direct somatic embryogenesis in Coffea canephora, In: Loyola-Vargas VM, 688 Vázquez-Flota FA eds. Plant cell culture protocols. Totowa, New Jersey: Humana 689 Press, 111. DOI: 10.1385/1-59259-959-1:111. 
690 Rademacher EH, Möller B, Lokerse AS, Llavata-Peris Cl, van den Berg W, Weijers D. 691 2011. A cellular expression map of the Arabidopsis AUXIN RESPONSE FACTOR gene 692 family. The Plant Journal 68(4):597-606 DOI: 10.1111/j.1365-313X.2011.04710.x.

693 Rhee SY, Dickerson J, Xu D. 2006. Bioinformatics and its applications in plant biology. 694 Annual Review of Plant Biology 57(1):335-360 DOI: 695 10.1146/annurev.arplant.56.032604.144103.

696 Sghaier N, Ben Ayed R, Ben Marzoug R, Rebai A. 2018. Dempster-Shafer theory for 697 the prediction of auxin-response elements (AuxREs) in plant genomes. BioMed 698 Research International 20183837060 DOI: https://doi.org/10.1155/2018/3837060.

699

700

701

702

703

704

705

706

707

708

709

710

711

712

Shi X, Zhang C, Liu Q, Zhang Z, Zheng B, Bao M. 2016. De novo comparative transcriptome analysis provides new insights into sucrose induced somatic embryogenesis in camphor tree (Cinnamomum camphora L.). BMC Genomics 17:26 DOI: 10.1186/s12864-015-2357-8.

Sisodia R,Bhatla SC. 2018. Embryogenesis, vegetative growth, and organogenesis, In: Bhatla SC, Lal A eds. Plant Physiology, Development and Metabolism. Singapore: Springer, 767. DOI: https://doi.org/10.1007/978-981-13-2023-1_24.

Su Y, Liu Y, Zhou C, Li X, Zhang X. 2016. The microRNA167 controls somatic embryogenesis in Arabidopsis through regulating its target genes ARF6 and ARF8. Plant Cell, Tissue and Organ Culture 124(2):405-417 DOI: 10.1007/s11240-015-0903-3.

Tao L, Zhao Y, Wu Y, Wang Q, Yuan H, Zhao L, Guo W, You X. 2016. Transcriptome profiling and digital gene expression by deep sequencing in early somatic embryogenesis of endangered medicinal Eleutherococcus senticosus Maxim. Gene 578(1):17-24 DOI: 10.1016/j.gene.2015.11.050.

713 Weijers D, Benková E, Jager KE, Schlereth A, Hamann T, Kientz M, Wilmoth JC, Reed 714 JW, Jurgens G. 2005. Developmental specificity of auxin response by pairs of ARF and 715 Aux/IAA transcriptional regulators. EMBO Journal 24(10):1874-1885 DOI: 716 10.1038/sj.emboj.7600659.

717 Weijers D, Wagner D. 2016. Transcriptional responses to the auxin hormone. Annual 718 Review of Plant Biology 67(1):539-574 DOI: 10.1146/annurev-arplant-043015-112122.

719 Wickham, H. 2016. Ggplot2: elegant graphics for data analysis. Switzerland: Springer.

720

721

722

723

724

725
Wójcikowska B, Gaj MD. 2017. Expression profiling of AUXIN RESPONSE FACTOR genes during somatic embryogenesis induction in Arabidopsis. Plant Cell Reports 36(6):843-858 DOI: 10.1007/s00299-017-2114-3.

Wojcikowska B, Gaj MD. 2017. Expression profiling of AUXIN RESPONSE FACTOR genes during somatic embryogenesis induction in Arabidopsis. Plant Cell Reports 36(6):843-858 DOI: 10.1007/s00299-017-2114-3. 
$726 \mathrm{Xu} \mathrm{J}$, Zhang S. 2015. Mitogen-activated protein kinase cascades in signaling plant

727 growth and development. Trends in Plant Science 20(1):56-64 DOI:

728 10.1016/j.tplants.2014.10.001.

729 Yakovlev IA, Carneros E, Lee Y, Olsen JE, Fossdal CG. 2016. Transcriptional profiling 730 of epigenetic regulators in somatic embryos during temperature induced formation of an 731 epigenetic memory in Norway spruce. Planta 243(5):1237-1249 DOI: 10.1007/s00425732 016-2484-8.

733 Yang X, Zhang X, Yuan D, Jin F, Zhang Y, Xu J. 2012. Transcript profiling reveals 734 complex auxin signalling pathway and transcription regulation involved in 735 dedifferentiation and redifferentiation during somatic embryogenesis in cotton. BMC 736 Plant Biology 12(1):110 DOI: 10.1186/1471-2229-12-110.

737 Yasuda T, Fujii Y, Yamaguchi T. 1985. Embryogenic callus induction from Coffea 738 arabica leaf explants by benzyladenine. Plant and Cell Physiology 26(3):595-597 DOI: 739 https://doi.org/10.1093/oxfordjournals.pcp.a076946.

740 Yuyama PM, Reis Júnior O, Ivamoto ST, Domingues DS, Carazzolle MF, Pereira GAG, 741 Charmetant P, Leroy T, Pereira LFP. 2016. Transcriptome analysis in Coffea 742 eugenioides, an Arabica coffee ancestor, reveals differentially expressed genes in 743 leaves and fruits. Molecular Genetics and Genomics 291(1):323-336 DOI: 744 https://doi.org/10.1007/s00438-015-1111-x.

745 Zhang H, Chen J, Zhang F, Song Y. 2019. Transcriptome analysis of callus from melon. 746 Gene 684:131-138 DOI: https://doi.org/10.1016/j.gene.2018.10.037. 


\section{Legends for figures}

751 Figure 1. Description of the stages, days, culture medium and tissues that comprise the 752 process of somatic embryogenesis induction in C. canephora.

753 Figure 2. Process of somatic embryogenesis induction in C. canephora. A) Plantlet in 754 pre-conditioning stage in MS medium added with $0.54 \mu \mathrm{M} \mathrm{NAA}$ and $2.32 \mu \mathrm{M} \mathrm{KIN}$. B) 755 Explant at 14 days after induction in Yasuda's medium (Yasuda, Fujii, Yamaguchi, 756 1985) supplemented with $5 \mu \mathrm{M}$ BA. C) Explant 21 days after induction of SE. D) 757 Explants 56 days after induction of SE. E) Embryos at germination stage, in MS medium 758 without PGR. J) Complete plantlets regenerated from somatic embryos. Scale bars: 1 759 $\mathrm{cm}(A, D, F), 0.2 \mathrm{~cm}(B, C), 0.5 \mathrm{~cm}(E)$.

760 Figure 3. Heatmap of the expression profile of 25574 genes of $C$. canephora during the 761 different stages of the process of SE induction.

762 Figure 4. Expression profile of genes involved in IAA signaling during the different 763 stages of the process of SE induction. A) Auxin Response Factor (ARF). B) Aux/IAA. 764 (Arrows indicate the genes selected for quantification by qPCR).

765 Figure 5. Number of differentially expressed genes at different stages of the process of 766 SE induction, when comparing $14 \mathrm{DBI}$ (control) against 9 and $0 \mathrm{DBI}$, and 1, 2 and 21 767 DAI.

768 Figure 6. Venn diagram of differentially expressed genes between each comparison. 769 The overlapping regions correspond to the number of DEG shared between each point 770 of the process of SE induction.

771 Figure 7. Quantification of the relative expression level (qPCR) of certain genes related 772 to auxin signaling during SE induction in C. canephora.

773

774 Legends for tables 
775 Table 1. Sample description and basic statistics of RNA-seq data libraries of $C$. 776 canephora's transcriptome corresponding to SE induction.

777 Table 2. Differentially expressed ARF and Aux/IAA genes, during the process of SE 778 induction in C. canephora.

779

780

781 Legends for supplementary files

782 Figure S1. Pearson's correlation coefficient between replicas for each sampling day.

783 Table S1. Primers designed for quantification of relative expression by qPCR.

784 Table S2. Results from the alignment of reads from each sample to the $C$. canephora 785 genome.

786 Table S3. Orthology analysis between C. canephora and A. thaliana.

787 Fasta sequences of ARF and Aux/IAA genes present in C. canephora. 


\section{Figure 1}

Somatic embryogenesis induction in C. canephora

Description of the stages, days, culture medium and tissues that comprise the process of somatic embryogenesis induction in C. canephora

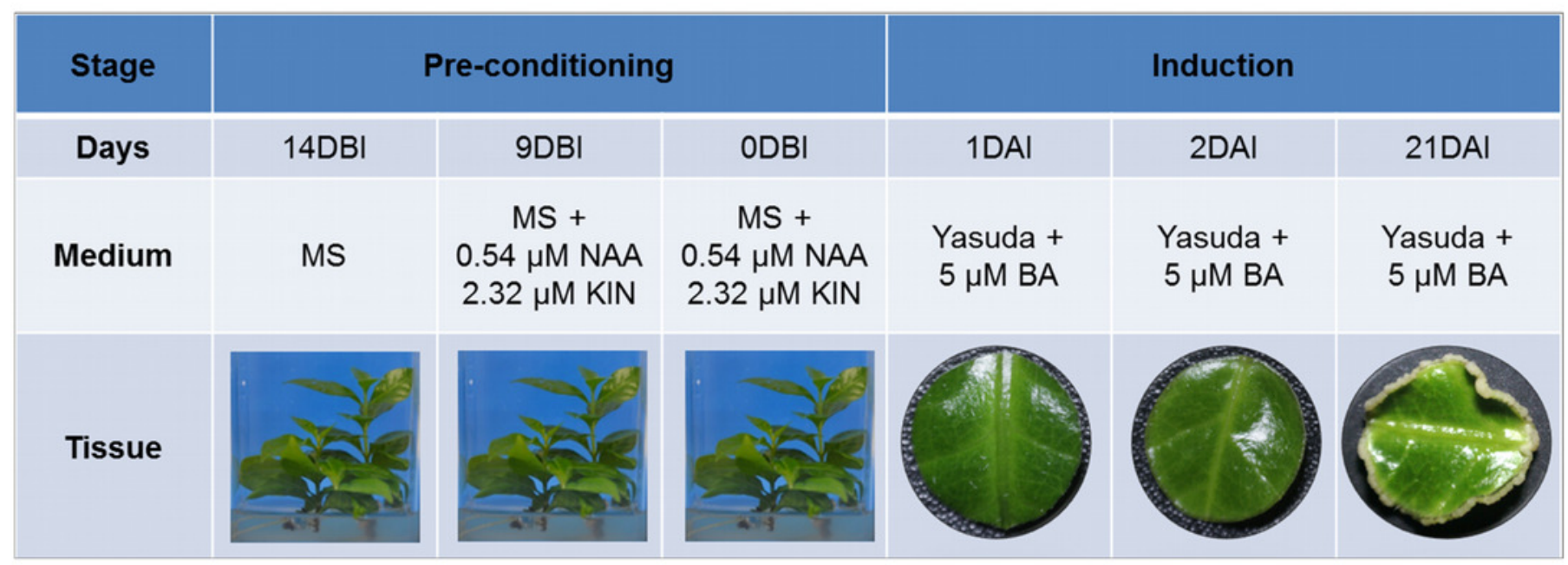




\section{Figure 2}

Process of somatic embryogenesis induction in C. canephora.

A) Plantlet in pre-conditioning stage in MS medium added with $0.54 \mu \mathrm{M}$ NAA and $2.32 \mu \mathrm{M} \mathrm{KIN}$.

B) Explant at 14 days after induction in Yasuda's medium (Yasuda, Fujii, Yamaguchi, 1985) supplemented with $5 \mu \mathrm{M}$ BA. C) Explant 21 days after induction of SE. D) Explants 56 days after induction of SE. E) Embryos at germination stage, in MS medium without PGR. J)

Complete plantlets regenerated from somatic embryos. Scale bars: $1 \mathrm{~cm}(A, D, F), 0.2 \mathrm{~cm}(B$, C), $0.5 \mathrm{~cm}(\mathrm{E})$.

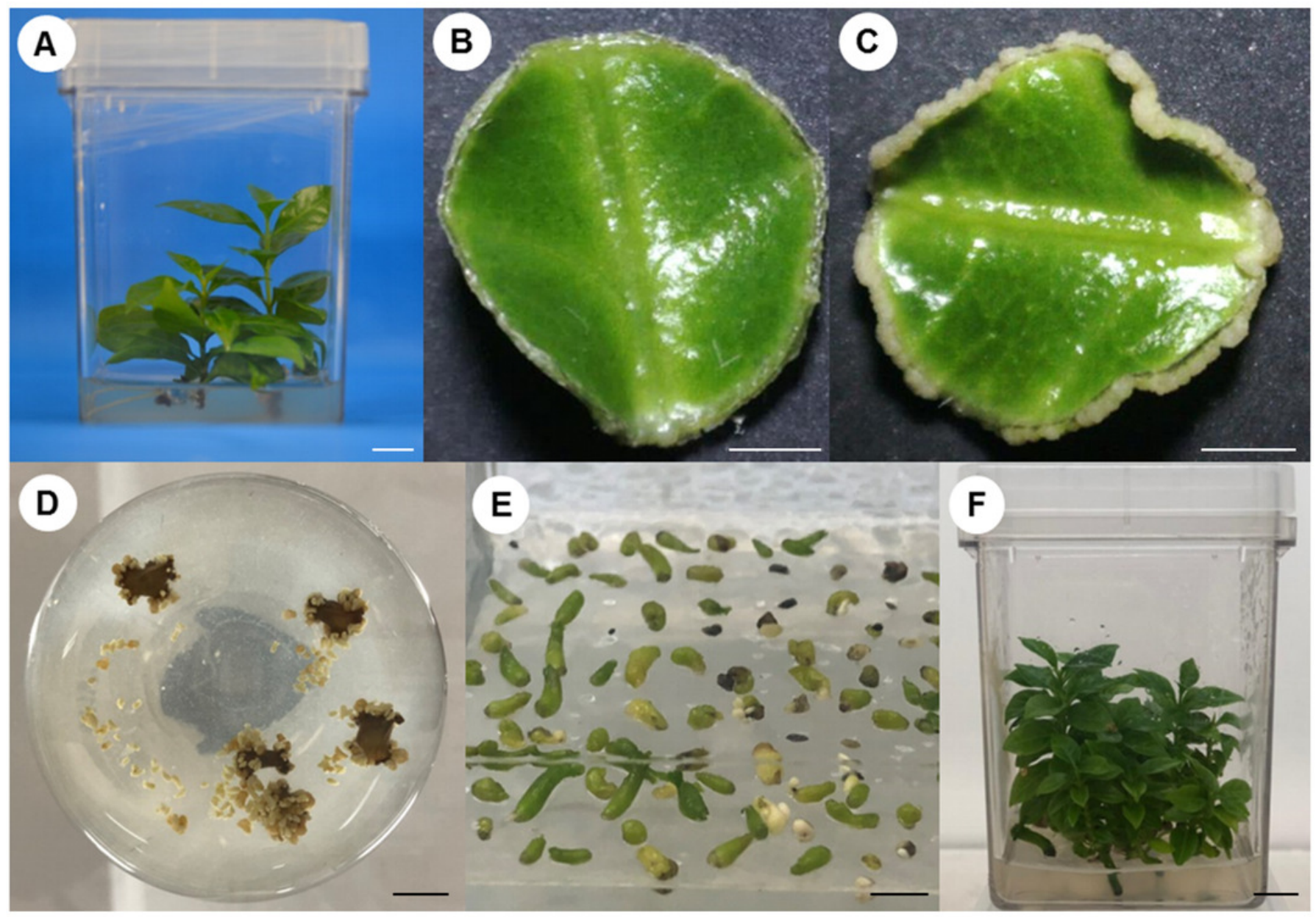




\section{Figure 3}

Expression profile of genes of $C$. canephora.

Heatmap of the expression profile of 25574 genes of $C$. canephora during the different stages of the process of SE induction

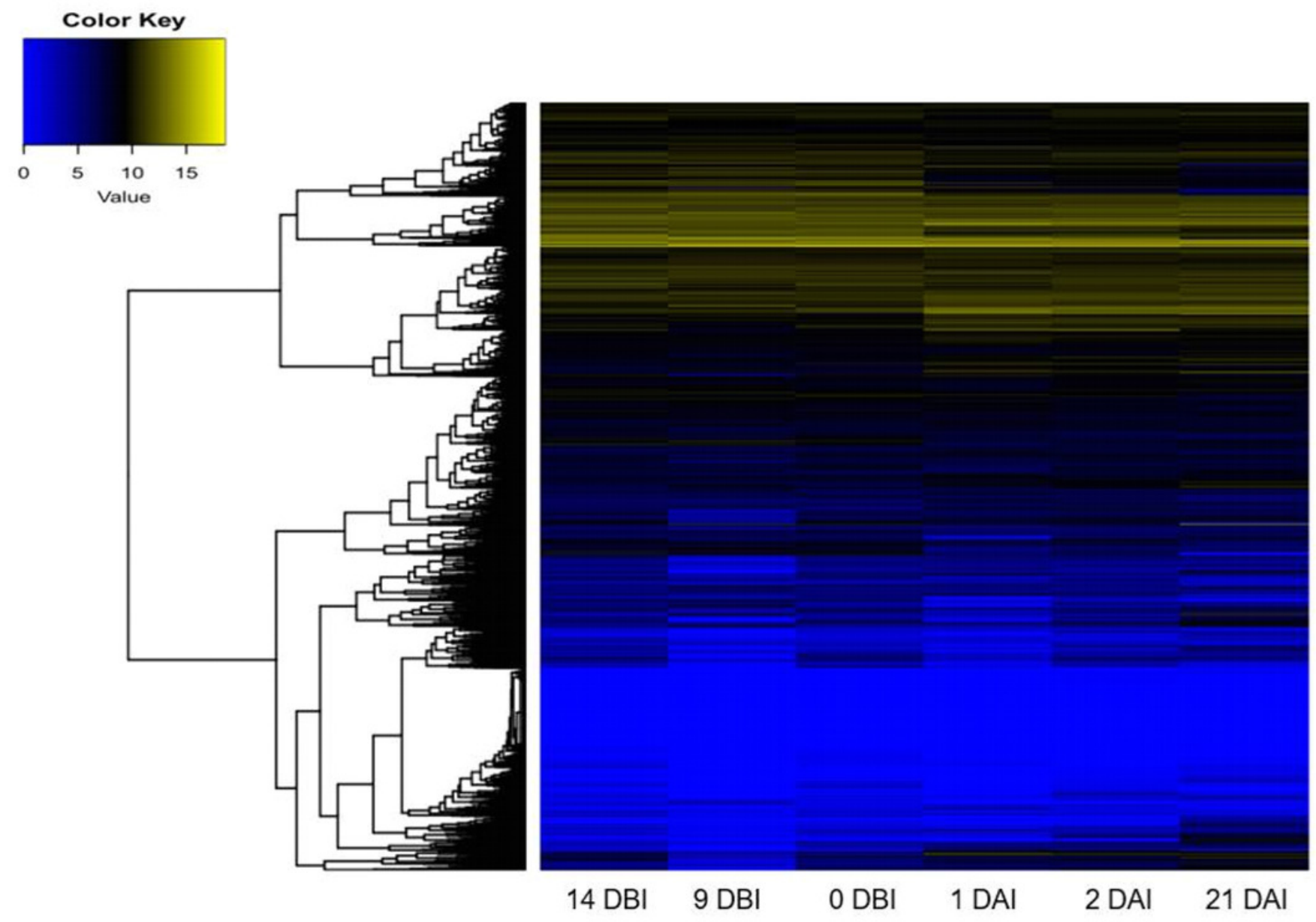


Figure 4

Expression profile of genes involved in IAA signaling during the different stages of the process of SE induction.
A) Auxin Response Factor (ARF). B) Aux/IAA. (Arrows indicate the genes selected for quantification by qPCR). 

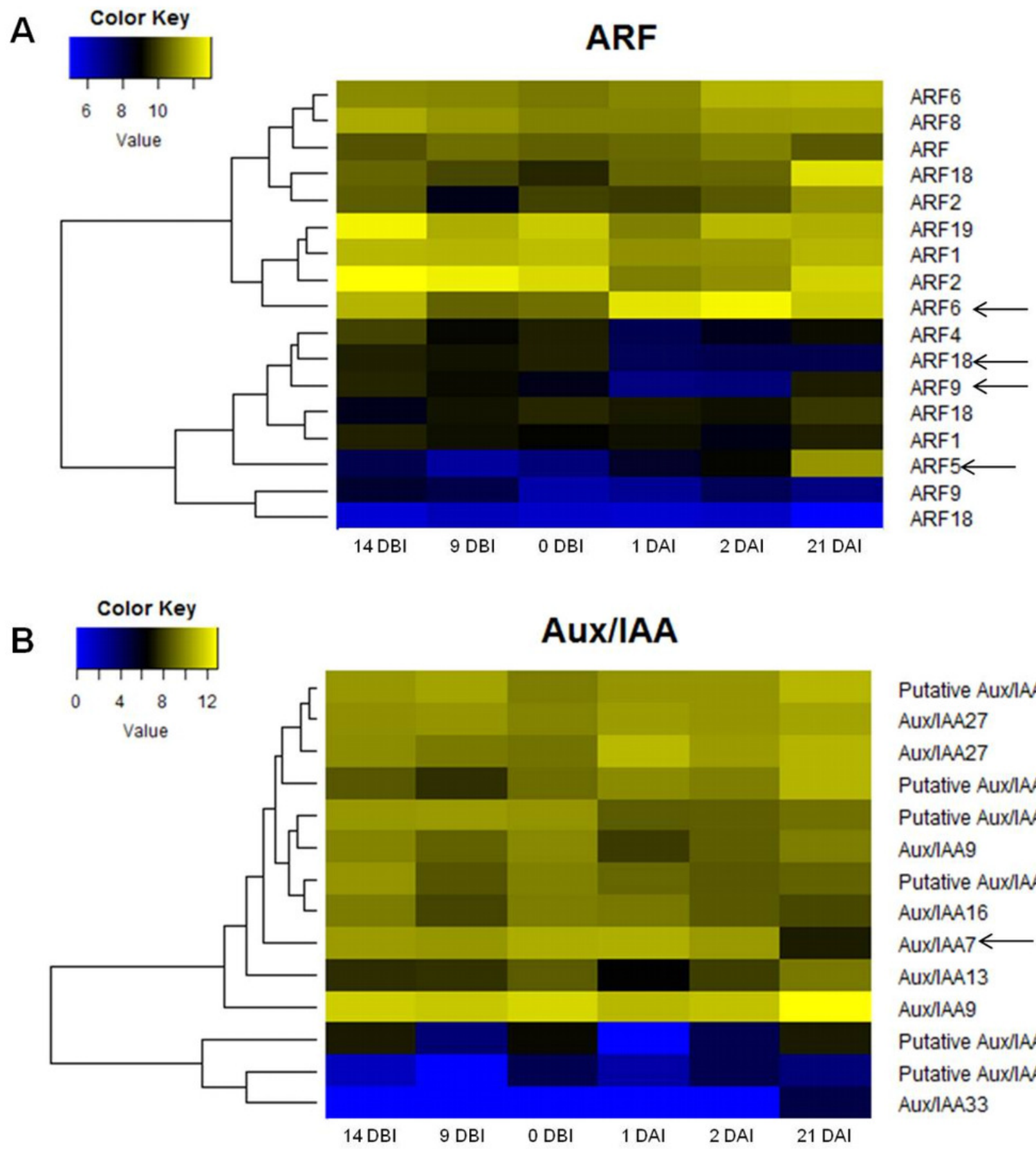

Putative Aux/IAA18 Aux/IAA27 Aux/IAA27

Putative Aux/IAA29

Putative Aux/IAA12 $\longleftarrow$ Aux/IAA9

Putative Aux/IAA16 Aux/IAA16 Auxl|AA7 $\longleftarrow$ AuxlIAA13 Aux/AA9

Putative Aux/IAA29 Putative Aux/AA32 Aux/IAA33 


\section{Figure 5}

Differentially expressed genes.

Number of differentially expressed genes at different stages of the process of SE induction, when comparing $14 \mathrm{DBI}$ (control) against 9 and $0 \mathrm{DBI}$, and 1, 2 and 21 DAI.

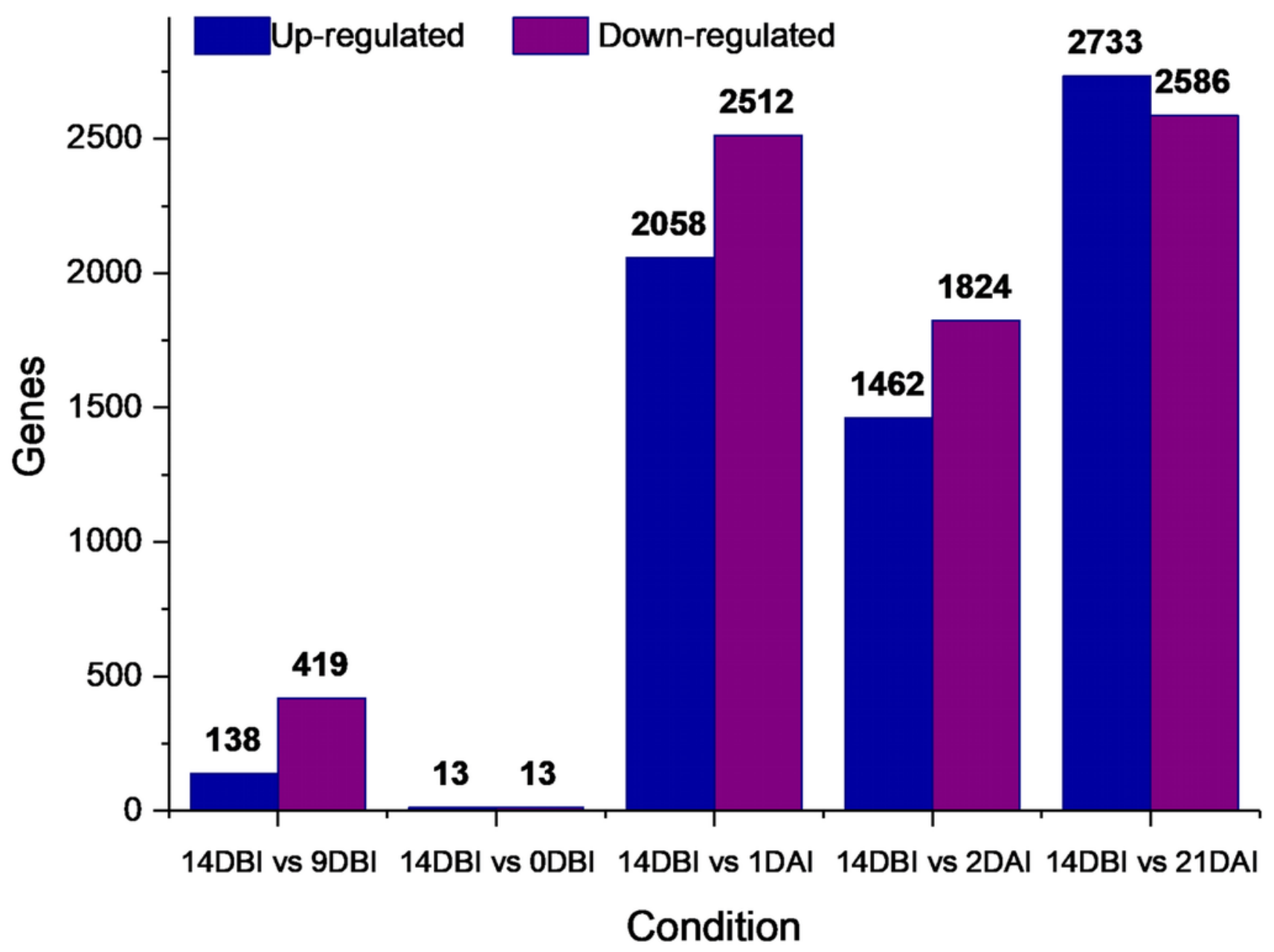




\section{Figure 6}

Venn diagram of differentially expressed genes between each comparison.

The overlapping regions correspond to the number of DEG shared between each point of the process of SE induction.

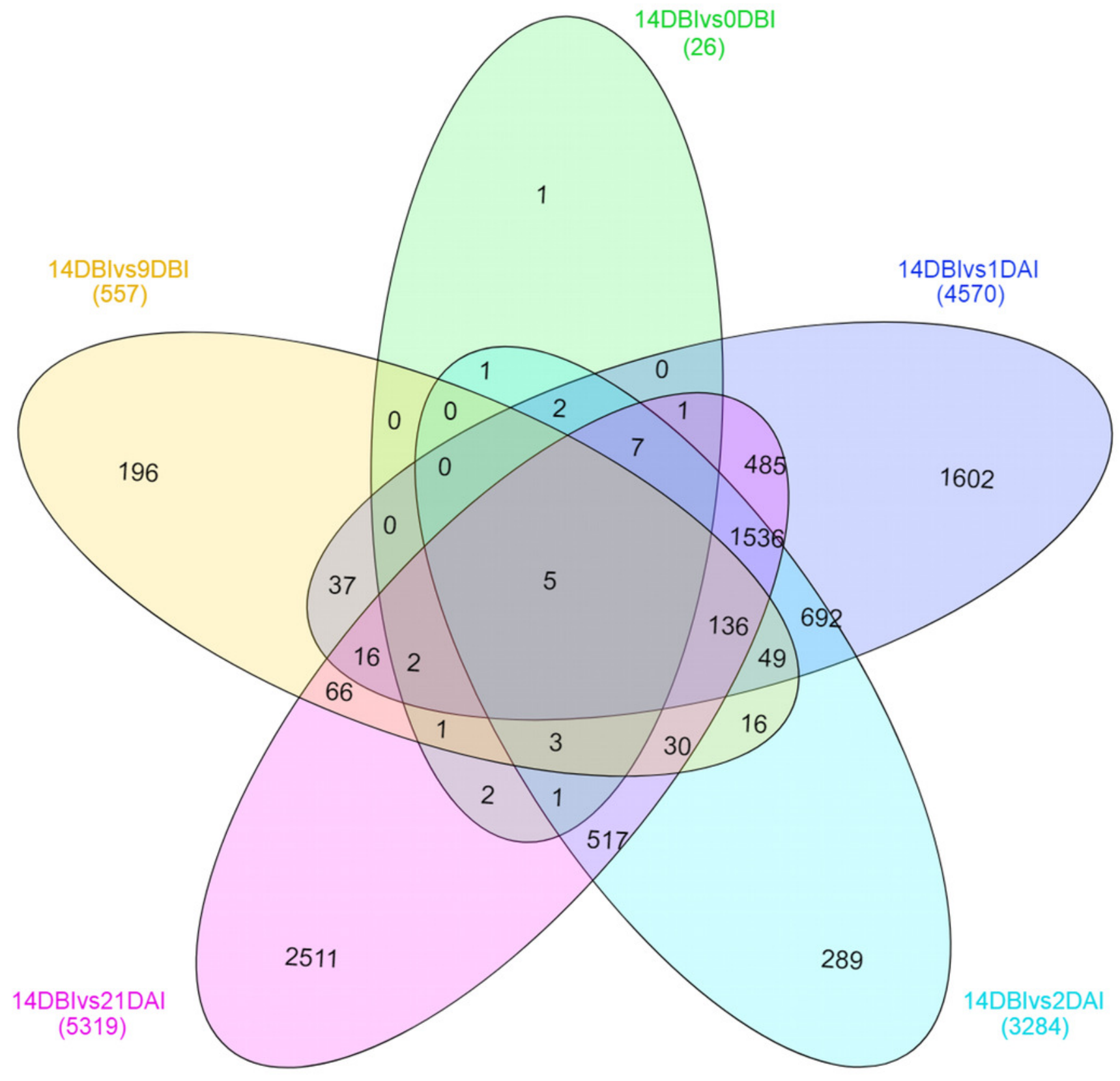


Figure 7

Relative expression level

Quantification of the relative expression level (qPCR) of certain genes related to auxin signaling during SE induction in C. canephora. 
A

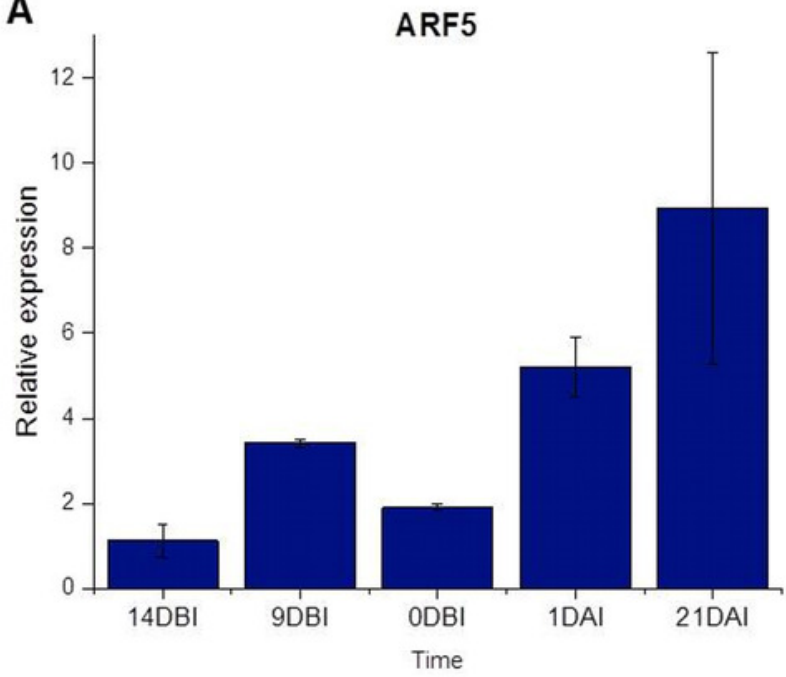

C

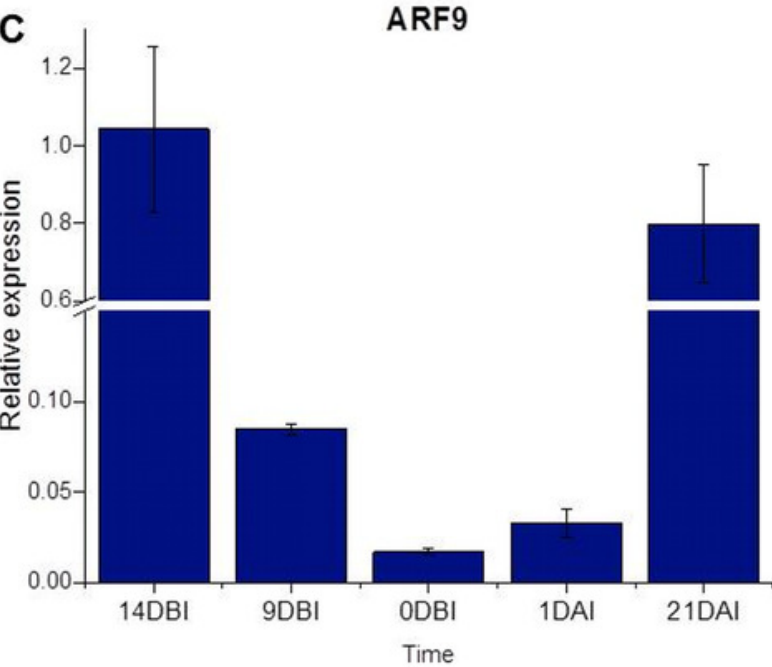

E

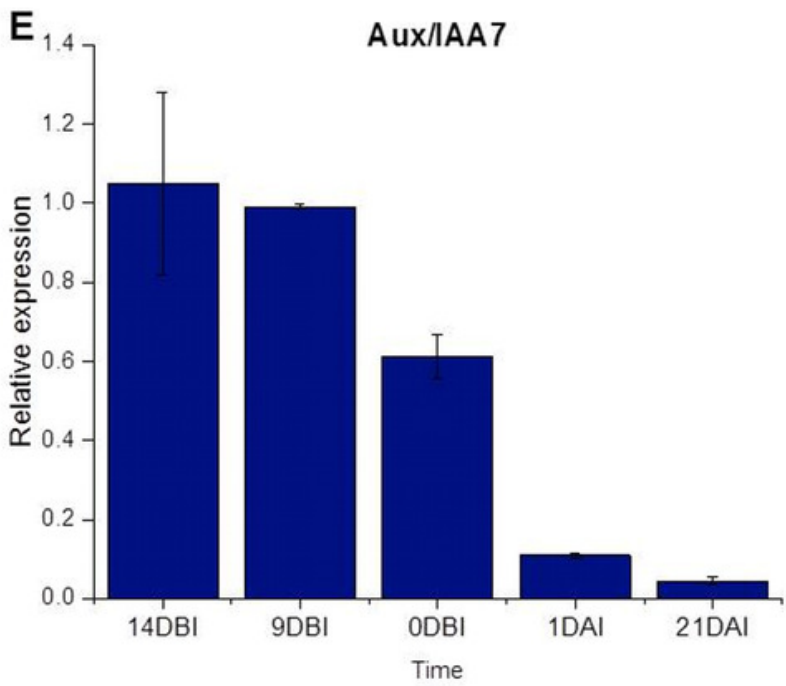

B
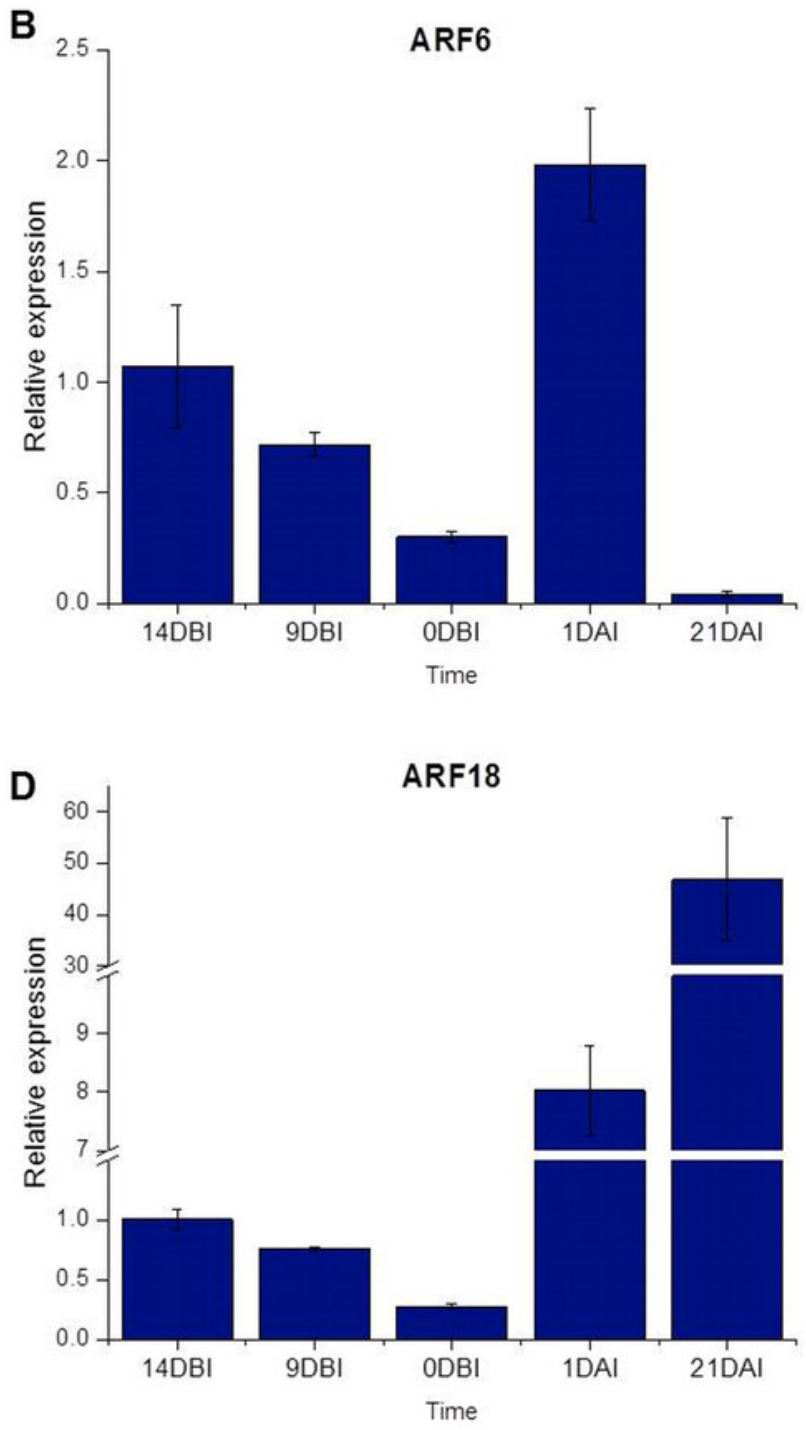

$\mathbf{F}$

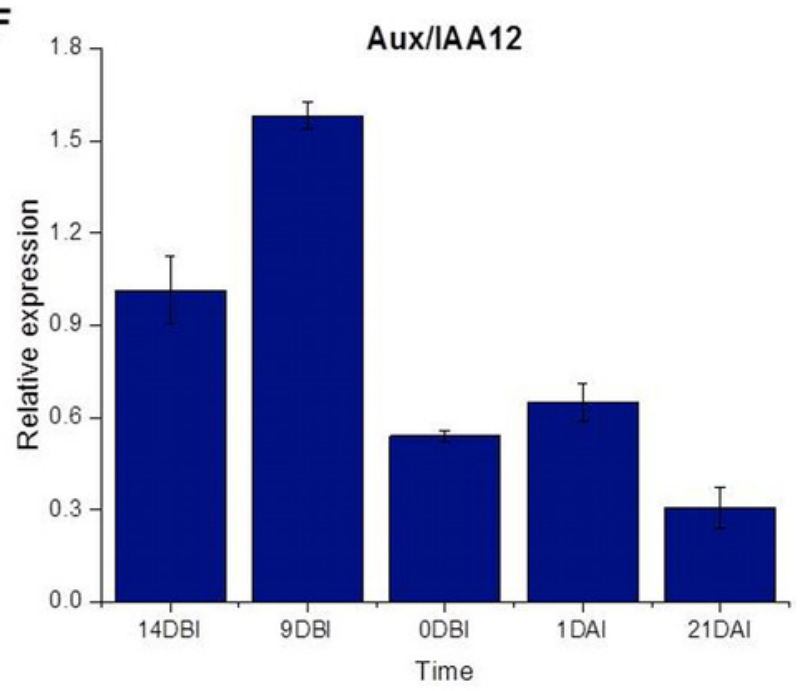




\section{Table 1 (on next page)}

Sample description and basic statistics of RNA-seq data libraries of $C$. canephora's transcriptome corresponding to SE induction.

Sample description and basic statistics of RNA-seq data libraries of $C$. canephora's transcriptome corresponding to SE induction. 
2 Table 1. Sample description and basic statistics of RNA-seq data libraries of $C$. 3 canephora transcriptome.

\begin{tabular}{|c|c|c|c|c|c|}
\hline Sample & Treatment & $\begin{array}{c}\text { Raw } \\
\text { sequences }\end{array}$ & $\begin{array}{l}\text { High-quality } \\
\text { sequences }\end{array}$ & $\begin{array}{c}\text { Rate of } \\
\text { recovered } \\
\text { sequences } \\
(\%)\end{array}$ & $\begin{array}{c}\text { Overall } \\
\text { alignment rate } \\
(\%)\end{array}$ \\
\hline 14_1 DBI & \multirow{2}{*}{ Pre-conditioning } & $42,157,360$ & $38,064,798$ & 90.29 & 60.97 \\
\hline 14_2 DBI & & $44,738,607$ & $44,737,035$ & 100.00 & 75.17 \\
\hline 9_1 DBI & \multirow{2}{*}{ Pre-conditioning } & $43,459,278$ & $40,731,459$ & 93.72 & 66.03 \\
\hline 9_2 DBI & & $43,628,937$ & $42,369,506$ & 97.11 & 68.52 \\
\hline 0_1 DBI & \multirow{2}{*}{ Pre-conditioning } & $40,924,936$ & $38,247,628$ & 93.46 & 69.29 \\
\hline 0_2 DBI & & $49,032,211$ & $49,012,743$ & 99.96 & 73.88 \\
\hline 1_1 DAI & \multirow{2}{*}{ Induction } & $38,121,519$ & $33,791,596$ & 88.64 & 66.58 \\
\hline 1_2 DAl & & $49,094,305$ & $44,718,468$ & 91.09 & 70.24 \\
\hline 2_1 DAl & \multirow{2}{*}{ Induction } & $62,157,781$ & $54,777,604$ & 88.13 & 66.43 \\
\hline 2_2 DAl & & $61,989,925$ & $61,987,800$ & 100.00 & 76.20 \\
\hline 21_1 DAI & \multirow{2}{*}{ Induction } & $39,436,806$ & $34,526,731$ & 87.55 & 54.13 \\
\hline 21_2 DAI & & $51,508,818$ & $51,504,421$ & 99.99 & 76.95 \\
\hline
\end{tabular}

4

5

6

7 


\section{Table 2 (on next page)}

Fold change values of differentially expressed ARF and Aux/IAA genes during the process of SE induction in C. canephora.

Fold change values of differentially expressed ARF and Aux/IAA genes during the process of $\mathrm{SE}$ induction in C. canephora. 
1 Table 2. Differentially expressed ARF and Aux/IAA genes, during the process of SE induction in C. canephora.

\begin{tabular}{|c|c|c|c|c|c|c|c|c|c|c|}
\hline \multirow[b]{2}{*}{ Gene ID } & \multirow[b]{2}{*}{ Contig name } & \multicolumn{3}{|c|}{14 DBI vs 1 DAI } & \multicolumn{3}{|c|}{$14 \mathrm{DBI}$ vs $2 \mathrm{DAI}$} & \multicolumn{3}{|c|}{$14 \mathrm{DBI}$ vs $21 \mathrm{DAl}$} \\
\hline & & LFC & $P$ value & $P$-adj & LFC & $P$ value & $P$-adj & LFC & $P$ value & $P$-adj \\
\hline ARF2 & Cc00_g12260 & -2.1 & $2.5 \mathrm{E}-10$ & $1.0 \mathrm{E}-08$ & -1.8 & $6.7 \mathrm{E}-06$ & 1.3E-04 & - & - & - \\
\hline ARF4 & Cc01_g11410 & -2.6 & $1.6 \mathrm{E}-04$ & $1.5 \mathrm{E}-03$ & - & - & - & - & - & - \\
\hline ARF5 & Cc10_g01900 & - & - & - & 1.3 & 4.7E-03 & $3.2 \mathrm{E}-02$ & 3.4 & 2.7E-11 & $8.2 \mathrm{E}-10$ \\
\hline ARF6 & Cc09_g08740 & - & - & - & 1.1 & 7.8E-03 & 4.8E-02 & - & - & - \\
\hline ARF9 & Cc08_g16330 & -2.7 & $9.5 \mathrm{E}-07$ & 1.7E-05 & -2.5 & 3.7E-06 & 7.4E-05 & - & - & - \\
\hline ARF18 & Cc01_g11020 & - & - & - & - & - & - & 2.0 & $1.8 \mathrm{E}-03$ & $9.8 \mathrm{E}-03$ \\
\hline ARF18 & Cc06_g03950 & -1.9 & $1.2 \mathrm{E}-04$ & 1.1E-03 & -1.7 & 3.7E-04 & 4.0E-03 & -1.8 & 1.7E-03 & 9.4E-03 \\
\hline ARF19 & Cc00_g00210 & -2.0 & $1.9 \mathrm{E}-04$ & 1.7E-03 & - & - & - & - & - & - \\
\hline IAA7 & Cc03_g04670 & - & - & - & - & - & - & -3.6 & $1.2 \mathrm{E}-07$ & 1.9E-06 \\
\hline IAA9 & Cc07_g07780 & -2.3 & 2.1E-03 & 1.3E-02 & - & - & - & - & - & - \\
\hline${ }^{*} \mathrm{P} . \mathrm{IAA} 12$ & Cc01_g17790 & -1.6 & $7.5 \mathrm{E}-04$ & $5.5 \mathrm{E}-03$ & -1.5 & $2.5 \mathrm{E}-03$ & $1.9 \mathrm{E}-02$ & - & - & - \\
\hline IAA13 & Cc03_g06400 & - & - & - & - & - & - & 1.8 & $5.2 \mathrm{E}-04$ & $3.5 \mathrm{E}-03$ \\
\hline${ }^{*}$ P. IAA29 & Cc06_g08150 & -11.1 & 2.1E-03 & 1.3E-02 & -4.2 & 4.6E-04 & 4.8E-03 & - & - & - \\
\hline${ }^{*}$ P. IAA29 & Cc08_g00560 & - & - & - & - & - & - & 2.0 & $5.5 \mathrm{E}-03$ & 2.6E-02 \\
\hline IAA33 & Cc06_g13230 & - & - & - & - & - & - & 7.3 & $1.0 \mathrm{E}-03$ & $6.1 \mathrm{E}-03$ \\
\hline
\end{tabular}

No differentially expressed genes were found at $9 \mathrm{DBI}$ and $0 \mathrm{DBI}$. Dashes means that genes were not detected as differentially expressed. *P: putative. 